\title{
Evaluation of the Global Climate Models in CMIP6 over Uganda
}

Hamida Ngoma ${ }^{1,4^{*}}$, Wang Wen ${ }^{1}$, Brian Ayugi ${ }^{1,2}$, Hassen Babaousmail ${ }^{3}$, Rizwan Karim ${ }^{1}$, Victor Ongoma ${ }^{5}$

${ }^{1}$ Key Laboratory of Meteorological Disaster, Ministry of Education (KLME)/Joint International Research Laboratory of Climate and Environment Change (ILCEC)/Collaborative Innovation Center on Forecast and Evaluation of Meteorological Disasters (CIC-FEMD), Nanjing University of Information Science and Technology, Nanjing 210044, China ; hamynads@gmail.com(H.N), wangwen@nuist.edu.cn (W.W), rizwan555danyore@gmail.com (R.K)

${ }^{2}$ Jiangsu Key Laboratory of Atmospheric Environment Monitoring and Pollution Control, Col laborative Innovation Center of Atmospheric Environment and Equipment Technology, Scho ol of Environmental Science and Engineering, Nanjing University of Information Science and Technology, Nanjing 210044, China; ayugi.o@gmail.com (B.A)

${ }^{3}$ Binjiang College of Nanjing University of Information Science and Technology, Jiangsu, Wuxi, China; baw.hassan47@gmail.com (H.B)

${ }^{4}$ Makerere University, Department of Geography, Geoinformatics and Climatic Sciences, P.O. Box 7062 Kampala Uganda; hamynads@gmail.com (H.N)

${ }^{5}$ International Water Research Institute, Mohammed VI Polytechnic University, Lot 660, Hay Moulay Rachid, Ben Guerir, 43150, Morocco; victor.ongoma@gmail.com (V.O)

*Correspondence: hamynads@gmail.com

\section{Abstract}

This study employed 15 CMIP6 GCMs and evaluated their ability to simulate rainfall over Uganda during 1981-2019. The models and the ensemble mean were assessed based on the ability to reproduce the annual climatologyseasonal rainfall distribution, trend, and statistical metrics, including mean bias error, root mean square error, and pattern correlation coefficient. The Taylor diagram and Taylor skill score (TSS) were used in ranking the models. The models performance varies greatly from one season to the other. The models reproduced the observed bimodal rainfall pattern of March to May (MAM) and September to November (SON) rains occurring over the region. Some models slightly overestimated, while some slightly underestimated, the MAM rainfall. However, there was a high rainfall overestimation during SON by most models. The models showed a positive spatial correlation with observed dataset, whereas a low correlation was shown interannually. Some models could not capture the rainfall patterns around local-scale features, for example, around the Lake Victoria basin and mountainous areas. The best performing models identified in the study include GFDL-ESM4, BCC-CMC-MR, IPSL-CM6A-LR, CanESM5, GDFL-CM4-gr1, and GFDL-CM4-gr2. The models CNRM-CM6-1 and CNRM-ESM2 underestimated rainfall throughout the annual cycle 
and mean climatology. However, these two models better reproduced the spatial trends of rainfall during both MAM and SON. The model spread in CMIP6 over the study area calls for further investigation on the attributions and possible implementation of robust approaches of Machine learning to minimize the biases.

Keywords: Rainfall, CMIP6, CHIRPS, Uganda, East Africa

\subsection{Introduction}

Precipitation remains the most valuable weather parameter in the tropics, where Uganda lies. The precipitation over the zone is regulated by various mechanisms regulate rainfall over the area. These range from mesoscale and synoptic scale features to global teleconnections. Rainfall is the most dorminant form of precipitation over the region, and mainly influenced by the Inter-Tropical Convergence Zone (ITCZ) that oscillates north-south throughout the year (Nicholson, 1996; Nicholson, 2018). The region experiences a bimodal rainfall pattern with 'long rains' from March to May (MAM) and 'short rains' from September to November (SON). The economy of the region largely depends on rainfed agriculture (Nsubuga et al., 2017).

Unfortunately, the region has been characterized by high spatio-temporal variation in precipitation in the past years (Basalirwa, 1995; Nicholson, 2007; Nsubuga et al., 2014, 2017). Past studies have reported a decline in MAM rain, whereas an increase in rainfall during SON is observed (Yang et al., 2014; Egeru et al., 2019; Ngoma et al., 2020). This shift in rainfall patterns has resulted in extreme events like droughts and floods (Mulinde et al., 2016; Nicholson, 2017; Ojara et al., 2020). According to the National Adaptation Programmes of Action, the wet areas of Uganda, i.e., around the Lake Victoria basin and east and northwest, tend to become wetter (GOU, 2015). These situations have resulted in the destruction of property and loss of livelihood (GOU, 2015).

The observed impacts of observed changes in rainfall calls for understanding the future changes for informed decision making while planning. The projected future rainfall is mainly based on simulations of General circulation models (GCMs). Various studies have been carried out over the African continent with the use of either GCMs or regional climate models (RCMs), at continental, subcontinental or country scale (Endris et al., 2013; Ogwang et al., 2014, 2015,2016; Mugume et al. 2017; Akinsanola et al., 2017; Osima et al., 2018; Kisembe et al., 2019; Ayugi et al., 2020). Over East Africa, several studies have used the GCMs, including Yang et al. (2015), Ongoma et al. (2019), Mumo and Yu (2020). Past studies that evaluated 
CMIP5 over East Africa reported a relatively poor performance of the models in simulating rainfall over the region (Akurut et al., 2014; Onyutha et al., 2016, 2019; Yang et al., 2015; Ongoma et al., 2019; Mumo et al., 2020). According to these studies, the models highly overestimated SON rains but undersimulated the MAM rainfall. However, some of the models depicted a difference in peak of the MAM seasonal rainfall which occurs in April as some showed peaks in May and March. A few studies (Akurut et al., 2014; Onyutha et al., 2016, 2019) have been conducted in Uganda based on GCMs, particularly Coupled Model Intercomparison Project (CMIP) output. These studies were carried out over a small domain of the Lake Victoria basin. Therefore, a national study is needed to evaluate the performance of the GCMs in reproducing rainfall over the study region.

CMIP outputs have been widely used in many climate change studies and in developing the assessment reports of the Inter-governmental Panel on Climate Change (IPCC) (IPCC, 2012, 2013). The latest output from the World Climate Research Programme (WCRP) is phase six (CMIP6) of the CMIP project (Eyring et al., 2016). The models have an additional value in the parameterization schemes for the climate system's major physical and biogeochemical processes compared to the previous version of CMIP5 (Taylor et al., 2012). Recent studies that have utilized CMIP6 have reported that the models exhibited improvements compared to CMIP5 (Akinsanola et al., 2020; Almazroui et al., 2020a,b; Zhu et al., 2020). So far, only one study (Almazroui et al., 2020b) has utilized the CMIP6 models over Africa. The study covered the entire continent. Thus, regionalized studies are needed to evaluate the GCMs before predicting future regional climate.

This study evaluates the ability of the CMIP6 in simulating mean rainfall over Uganda and selects the best performing models which will be used to generate a multi-model ensemble mean for projecting rainfall patterns over the region. The study is divided into three sections. Section 1 gives the introduction and background of this study. Section 2 gives a brief description of the study domain, the datasets, and methods employed in the study. Section 3 presents the results and discussion under sub-topics, annual rainfall cycle, seasonal analysis, temporal distribution, linear trend, temporal statistical metrics, spatial statistical metrics, and lastly, model ranking. Section 4 gives the summary and conclusion.

\section{Study Area, Data and Methods}

\subsection{Study Area}


Uganda lies within East Africa, bounded by the geographical coordinates of longitudes $29^{\circ} \mathrm{E}$ to $35.2^{\circ} \mathrm{E}$ and latitudes $1.5^{\circ} \mathrm{S}$ to $4.5^{\circ} \mathrm{N}$. The total territorial domain is $241,038 \mathrm{~km}^{2}$, where land cover comprises up to $197,100 \mathrm{~km}^{2}$, and the remaining $43,938 \mathrm{~km}^{2}$ is covered by water. This includes the world's second-largest lake, Lake Victoria, located in the southern part of the country and shared with two neighboring countries Kenya ( 6\%) and Tanzania (49\%), with remaining section $(\sim 45 \%)$ in Uganda. The lowest elevation regions lie in the northwestern part around Lake Albert along the Rift Valley, while high elevation areas are in the southwest (Mts. Rwenzori and Mufumbira) and the east (Mts. Elgon and Moroto) of the country.

The climate of the region is mostly influenced by the ITCZ, interactions between the Indian and western Pacific oceans (ENSO), Congo air mass, local features (Basalirwa, 1995), and Indian Ocean Dipole (IOD) (Saji 1999). Some parts of the country in the north and southwest also receive enhanced rainfall from June to August (JJA), which is also attributed to moist westerlies from the Congo basin (Ogwang et al., 2015).

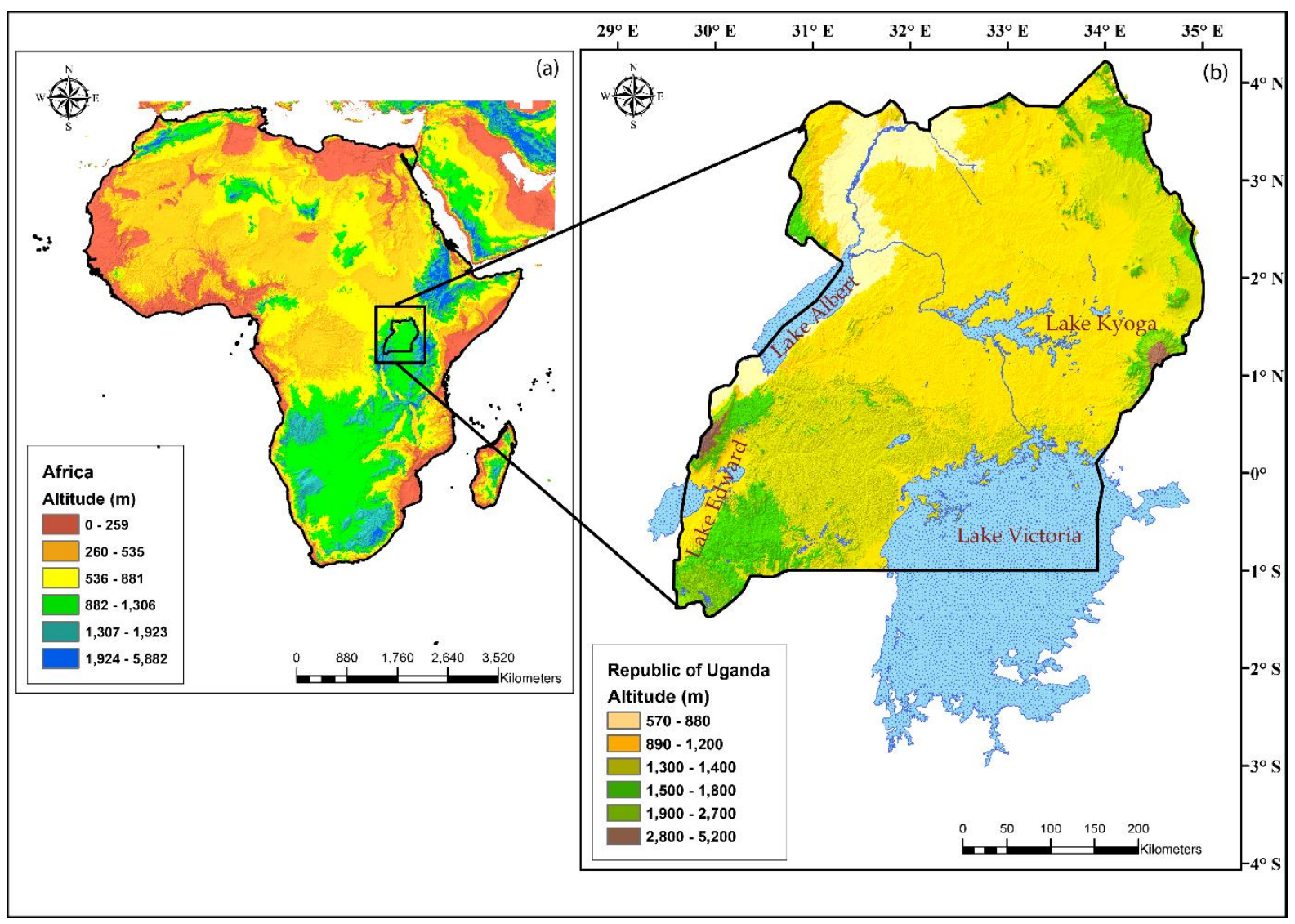

Figure 1. Location of Uganda in Africa along longitudes $29.2^{\circ} \mathrm{E}-35.2^{\circ} \mathrm{E}$ and latitudes $1.5^{\circ} \mathrm{S}$ $4.5^{\circ} \mathrm{N}$ (a) and (b) shows elevation (m) and physical features. The Lowest elevation is represented by light yellow in the northwest and the highest elevation by brown (Mt Rwenzori in the southwest and Mt Elgon in the east). 


\subsection{Data}

\subsubsection{Observed datasets}

Many discrepancies exist in ground station data over Africa, both in the temporal and spatial aspects (Sylla et al., 2012). Thus, as a proxy for observation, we utilized a monthly satellitegauge based dataset from the Climate Hazards Group Infrared Precipitation (CHIRPS.V2) (Funk et al., 2015). The CHIRPS.V2 data is built from smart interpolation technique and high resolution, long periods of precipitation estimates, and infrared cold cloud duration observations. It covers a spatial resolution of $0.05^{\circ} \times 0.05^{\circ}$, running from 1981 to date. CHIRPS.V2 data is preferred over other dataset because of its high resolution as well as its ability to capture the effects of topography and local features on rainfall over the study domain (Dinku et al., 2018; Ayugi et al., 2019; Ngoma et al., 2020).

\subsubsection{Climate Model Datasets}

The study utilized historical simulations of 15 GCMs from CMIP6 obtained from the Earth System Grid Data Portal - https://esgf-node.llnl.gov/search/cmip6. The basic information about the model datasets, the development centers, and their respective spatial resolution is given in Table 1. The study considered the ensemble of the first realization (r1i1p1f1) of the historical runs for all the models to ensure consistency in comparing and evaluating model performance against observation and to minimize the bias in the models . Although the models' historical runs are from 1850 to 2014, or 2015 for some models, this study covers the period 1981-2014 relative to the time frame of the gridded observation datasets to ensure consistency.

\subsection{Methods}

Firstly, averaged ensemble members of the first run of all the models were standardized to the international system (SI) unit for precipitation and set to a standard date format. The models were then re-gridded with a common grid of $1^{\circ} \times 1^{\circ}$ horizontal resolution using a remapping procedure of distance weighted (Isaaks and Srivastava, 1989). The ensemble of the models was generated by averaging all the models using a simple arithmetic mean technique. The models were then evaluated by examining their ability to reproduce the annual rainfall cycle and mean seasonal climatology for MAM and SON seasonal rainfall. The temporal rainfall distribution, and spatial and linear trends of the models were compared with observation data for further assessment. Theil's Sen Slope (Sen, 1968) was used to detect the magnitude of the trends, whilst Mann-Kendall (MK) test was applied to detect the significance of the trends (Mann, 
1945; Kendall, 1975). These approaches have been applied by various trend analysis studies (Ayugi et al., 2019; Rizwan et al., 2020).

The spatio-temporal performance of each model and the ensemble in simulating rainfall over the region were further assessed using statistical metrics including mean bias error (MBE), centered root mean square error (RMSE), and pattern correlation coefficient (CC). The Taylor diagram was used in the ranking of the models (Taylor, 2001). This approach has been employed in many studies (Kisembe et al., 2019; Ayugi et al., 2019, Ngoma et al., 2020) in ranking models' performance.

Furthermore, the Taylor skill score was used in ranking the models. Taylor skill score (TSS) calculated as Equation. (1) is a numerical summary of the Taylor diagram to express a synthetic measure.

$$
\mathrm{TSS}=\frac{4\left(1+R_{m}\right)^{2}}{\left(\frac{\sigma_{m}}{\sigma_{o}}+\frac{\sigma_{o}}{\sigma_{m}}\right)^{2}\left(1+R_{0}\right)^{2}}
$$

where $R_{m}$ is the spatial correlation coefficient of climatological mean between simulation and observation, $R_{o}$ is the maximum attainable correlation coefficient set here to 0.999 , and $\sigma_{m}$ and $\sigma_{o}$ are the standard deviations of the simulated and observed spatial patterns in climatological means, respectively. The closer is the value of TSS to 1 , the better is the agreement between the simulation and observation. Similar approach has been successfully employed in previous studies (i.e., Zhu et al., 2020; Luo et al., 2020; Xin et al., 2020)

Several studies have suggested that labeling of an ensemble as one GCM is not adequate to reproduce observed patterns (Kim et al., 2015; You et al., 2018). In addition, due to the inherent uncertainties of individual GCMs, the multi-model ensemble (MME) average generally provides more reliable and robust estimates than each individual model (Tebaldi and Knutti, 2007).

An ensemble of best performing models helps in reducing uncertainties among the models. Previous literature reveals no guideline for selecting the maximum number of GCMs in generating the ensemble. For example, Ongoma et al. (2019) and Ayugi et al. (2020) identified eight and five best performing models, respectively. Following recommendation of Ahmed et al. (2019), this study will identify top-ranked GCMS for the development of multimodel ensemble (MME), which is necessity in climate change impact assessment. 
Table 1: CMIP6 models employed in the study, the modeling centers, horizontal resolution and references.

\begin{tabular}{|c|c|c|c|c|}
\hline No & Models & Institution & Resolution & Reference \\
\hline 1 & $\begin{array}{l}\text { BCC-CSM2- } \\
\text { MR }\end{array}$ & $\begin{array}{l}\text { Beijing Climate Center (BCC) and China } \\
\text { Meteorological Administration (CMA), China }\end{array}$ & $1.13^{\circ} \times 1.13^{\circ}$ & Wu et al., 2018 \\
\hline 2 & BCC-ESM1 & $\begin{array}{l}\text { Beijing Climate Center (BCC) and China } \\
\text { Meteorological Administration } \\
\text { (CMA), China }\end{array}$ & $2.81 \times 2.81$ & $\begin{array}{l}\text { (Zhang et al., } \\
\text { (2018) }\end{array}$ \\
\hline 3 & CanESM5 & $\begin{array}{l}\text { Canadian Centre for Climate Modelling and } \\
\text { Analysis, Environment and Climate Change } \\
\text { Canada, Victoria, Canada }\end{array}$ & $2.81^{\circ} \times 2.81^{\circ}$ & $\begin{array}{l}\text { (Swart et al., } \\
\text { 2019) }\end{array}$ \\
\hline 4 & CESM2 & $\begin{array}{l}\text { National Center for Atmospheric Research, } \\
\text { USA }\end{array}$ & $1.25^{\circ} \times 0.94^{\circ}$ & $\begin{array}{l}\text { (Danabasoglu et } \\
\text { al., 2019) }\end{array}$ \\
\hline 5 & $\begin{array}{l}\text { CESM2- } \\
\text { WACCM }\end{array}$ & $\begin{array}{l}\text { National Center for Atmospheric Research, } \\
\text { USA }\end{array}$ & $1.25^{\circ} \times 0.94^{\circ}$ & $\begin{array}{l}\text { (Danabasoglu et } \\
\text { al., 2019) }\end{array}$ \\
\hline 6 & CNRM-CM6-1 & $\begin{array}{l}\text { Centre National de Recherches } \\
\text { Météorologiques (CNRM); Centre Européen } \\
\text { de Recherches et de } \\
\text { Formation Avancéeen Calcul Scientifique, } \\
\text { France }\end{array}$ & $1.41 \times 1.41$ & $\begin{array}{l}\text { Voldoire et al } \\
\text { (2019) }\end{array}$ \\
\hline 7 & $\begin{array}{l}\text { CNRM-ESM2- } \\
1\end{array}$ & $\begin{array}{l}\text { Centre National de Recherches } \\
\text { Meteorologiques, Toulouse, France }\end{array}$ & $1.41^{\circ} \times 1.41^{\circ}$ & (Seferian, 2018) \\
\hline 8 & $\begin{array}{l}\text { EC-EARTH3- } \\
\text { Veg }\end{array}$ & $\begin{array}{l}\text { Consortium of European research institution } \\
\text { and researchers, Europe }\end{array}$ & $0.70^{\circ} \times 0.70^{\circ}$ & $\begin{array}{l}\text { (EC-EARTH, } \\
\text { 2019a) }\end{array}$ \\
\hline 9 & GFDL-ESM4 & $\begin{array}{l}\text { Geophysical Fluid Dynamics Laboratory } \\
\text { (GFDL), USA }\end{array}$ & $1.25^{\circ} \mathrm{X} 1.00^{\circ}$ & $\begin{array}{l}\text { (Krasting et al., } \\
\text { 2018) }\end{array}$ \\
\hline 10 & $\begin{array}{l}\text { GFDL-CM4- } \\
\text { gr1 }\end{array}$ & $\begin{array}{l}\text { Geophysical Fluid Dynamics Laboratory } \\
\text { (GFDL), USA }\end{array}$ & $2.50 \times 2.00$ & $\begin{array}{l}\text { (Guo et al., } \\
\text { 2018) }\end{array}$ \\
\hline 11 & $\begin{array}{l}\text { GFDL-CM4- } \\
\text { gr1 }\end{array}$ & $\begin{array}{l}\text { Geophysical Fluid Dynamics Laboratory } \\
\text { (GFDL), USA }\end{array}$ & $2.50 \times 2.00$ & $\begin{array}{l}\text { (Guo et al., } \\
\text { 2018) }\end{array}$ \\
\hline 12 & $\begin{array}{l}\text { IPSL-CM6A- } \\
\text { LR }\end{array}$ & Institut Pierre Simon Laplace, Paris, France & $2.50^{\circ} \times 1.26^{\circ}$ & $\begin{array}{l}\text { (Boucher et al., } \\
\text { 2018) }\end{array}$ \\
\hline 13 & MRI-ESM2-0 & Meteorological Research Institute (MRI), Japan & $1.13^{\circ} \times 1.13^{\circ}$ & $\begin{array}{l}\text { (Yukimoto et al., } \\
\text { 2019) }\end{array}$ \\
\hline 14 & $\begin{array}{l}\text { SAM0- } \\
\text { UNICON }\end{array}$ & $\begin{array}{l}\text { Seoul National University, Seoul 08826, } \\
\text { Republic of Korea }\end{array}$ & $1.25^{\circ} \times 0.94^{\circ}$ & Park et al. (2019) \\
\hline 15 & $\begin{array}{l}\text { UKESMI } 1-0- \\
\text { LL }\end{array}$ & UK Met Office Hadley Center, UK & $1.88^{\circ} \times 1.25^{\circ}$ & Tang et al (2019) \\
\hline
\end{tabular}

\section{Results and Discussions}

\subsection{Annual cycle}

The model simulations reproduce bimodal rainfall patterns over Uganda, i.e., the long rains (MAM) and the short rains (SON), as shown in Figure 2. A good model is one that is able to reproduce the seasonality of a weather parameter, as stated by Sperber and Palmer (1996). The bimodal pattern is associated with the ITCZ's influence, which moves from north to south 
throughout the year (Nicholson, 2018; Nicholson et al., 2018).. Most of the models as well as the MME reproduce the June-August (JJA) seasonal rainfall, which is significant in some parts of the country, including the north and southwest areas. This is attributed to the influx of moist westerlies from the Congo basin (Basalirwa, 1995). However, there is an overestimation of SON rains by most of the models. The CNRM-CM6-1 and CNRM-ESM2-1 exhbit poor performance as they underestimate rainfall in all months. The ensemble mean captures the MAM seasonal cycle relatively well, whereas it overestimates the SON rains. This observation can be attributed to the large wet bias depicted by 13 out of 15 of all the models assessed. These results agree with previous studies (Yang et al., 2015; Ongoma et al., 2018; Mumo et al., 2020) carried out over East Africa based on CMIP5.

However, there is an improvement in the performance of the CMIP6 ensemble in reproducing the MAM rains as compared to MME of CMIP5, which showed a dry bias in replicating the seasonal MAM rains (Ongoma et al., 2019; Mumo et al., 2020). The MAM rainfall season is of great significance to the rain-fed agro-based economy of the country since the monthly rainfall influences the timing of crop planting and harvesting. With the wellpronounced ability of the models to reproduce the MAM rains, the future projection of its likelihood will be of great importance to the country's economy. Past studies have reported a paradox scenario over the long rains, which needs to be addressed. However, the overestimation of the SON rains can negatively impact farmers as they would expect more rainfall, and it turns out to be less than expected.

\subsection{Seasonal Analysis}

Annual rainfall over the region ranges between 500 and $2500 \mathrm{~mm}$ per year, with high spatial variability in rainfall across the region. High rainfall is received in the country's southern parts, around Lake Victoria, and in the eastern parts. On the other hand, low rainfall amounts have been recorded in the southwest, northeast, and northern parts of the country. Various mechanisms influence the rainfall over the region. The ITCZ, ENSO, IOD, Congo westerlies, and mesospheric effects are the most important Basalirwa (1995), Nicholson (1996), and Ogwang et al. (2014, 2015). The spatial distribution of seasonal rainfall for the CHIRPS and as simulated by models for MAM and SON is shown in Figures 3 and 4, respectively. Nearly 6 out of the 15 models underestimate MAM rainfall over most areas, whereas 8 models slightly overestimate the seasonal rain (Figure 3). However, most models tend to capture the higher rainfall amount over the Lake Victoria basin than other parts of the study area. This is attributed 
to mesospheric effects, including land and sea breeze (Nsubuga et al., 2014). Twelve models overestimate the SON rainfall spatial patterns over the area, while only two models, CNRMCM6-1 and CNRM-ESM2-1, reveal a dry bias (underestimate) for the SON rainfall's spatial distribution (Figure 4). The two models from the same parent institution fail to capture enhanced rainfall patterns around mountainous areas, for example, in the east around mountain Elgon. Various studies have linked this observation to parameterization skills in the models and low resolution, which cannot capture topographic effects (Ogwang et al., 2016; Kisembe et al., 2019). The UKESMI1-0-LL performed relatively better than other models in reproducing SON rainfall's spatial patterns

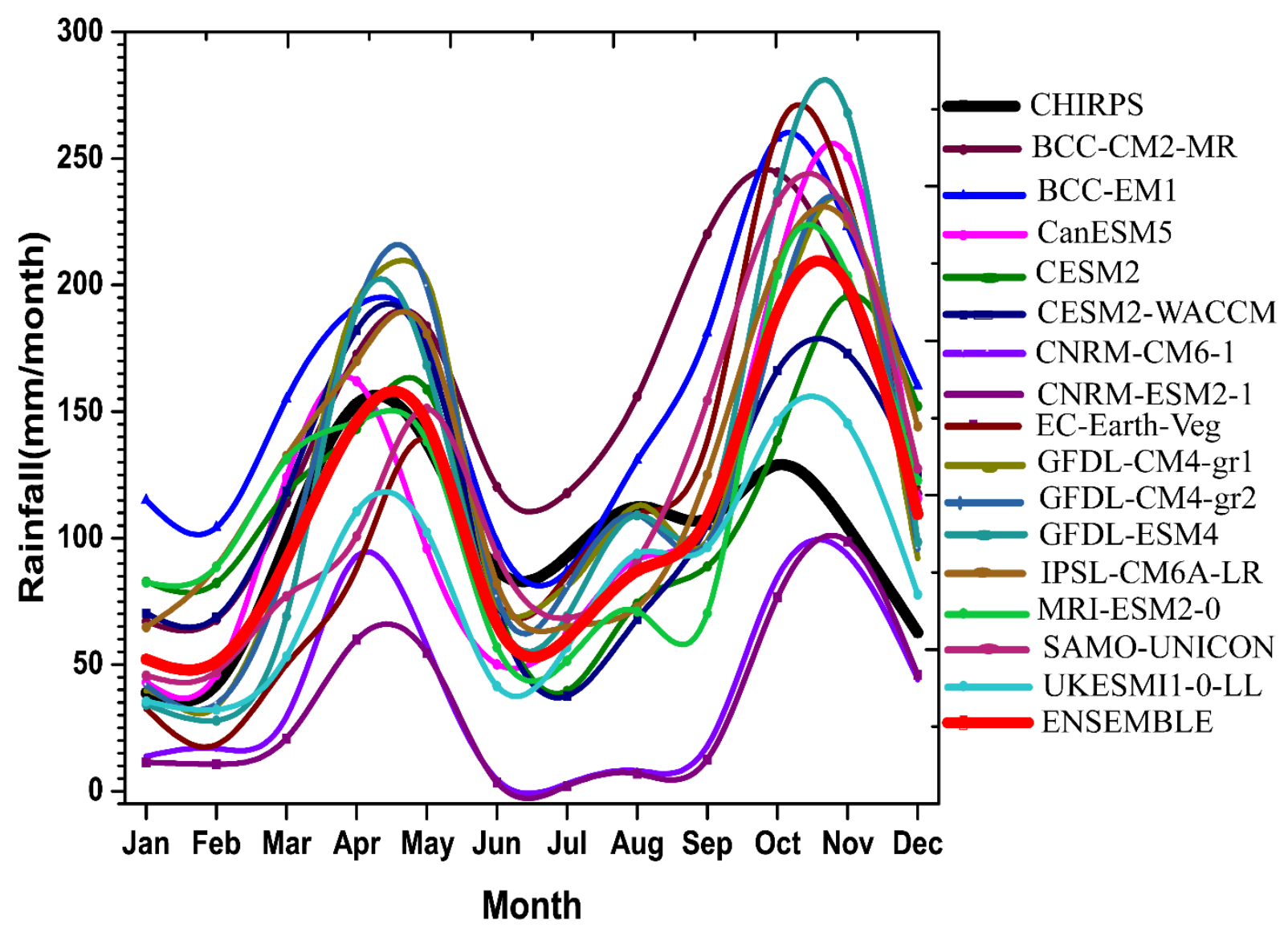

Figure 2. Mean annual cycle of rainfall over Uganda averaged between longitudes $29.2^{\circ} \mathrm{E}$ to $35.2^{\circ} \mathrm{E}$ and latitudes $1.5^{\circ} \mathrm{S}$ and $4.5^{\circ} \mathrm{N}$ for the period $1981-2014$, based on CHIRPS datasets, CMIP6 models and their ensemble mean. CHIRPS is represented by the thick black line and the ensemble by the thick red line. 

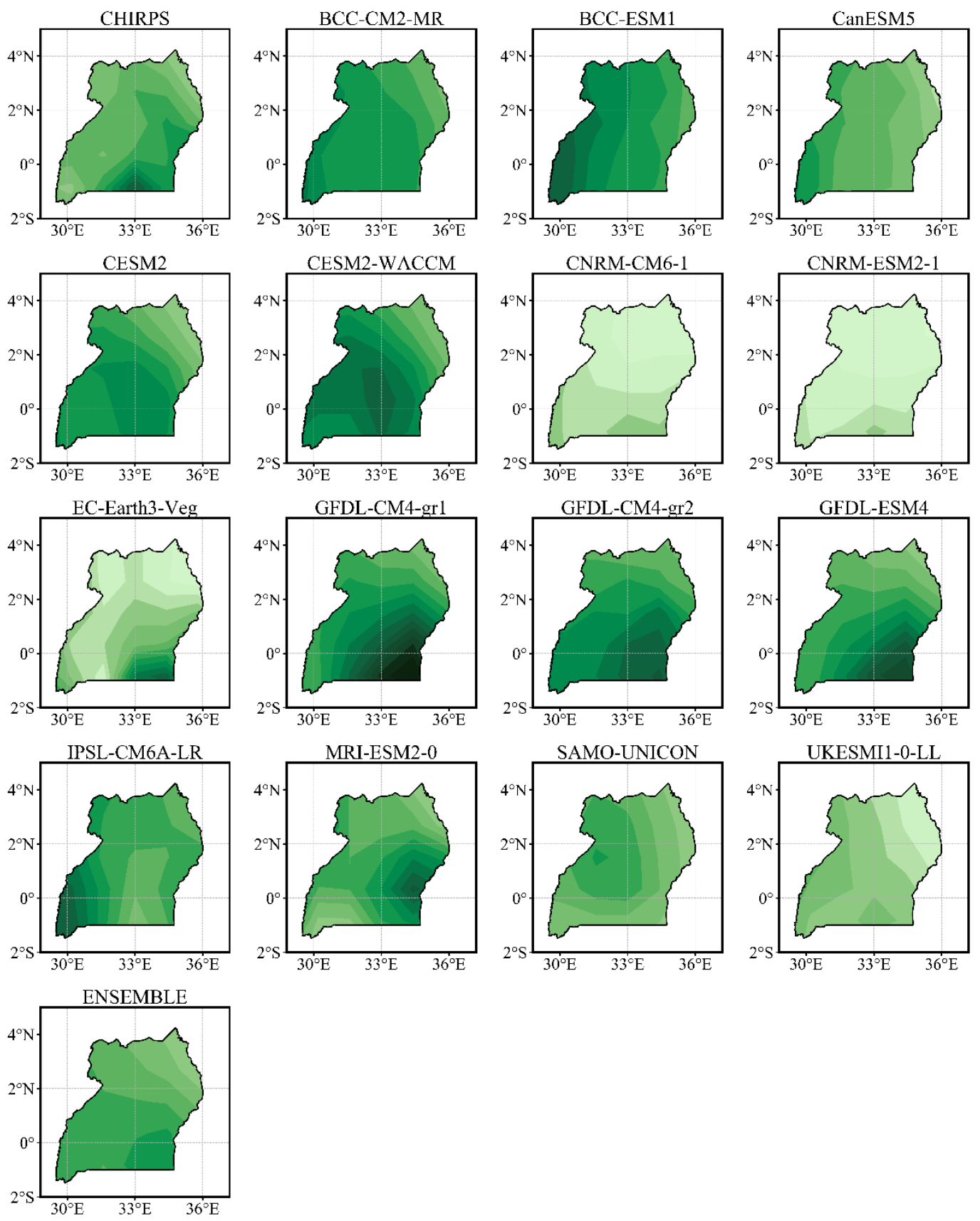

Figure 3. Spatial pattern of MAM mean monthly rainfall distribution over Uganda for CHIRPS, CMIP6 models and ensemble during 1981-2014. The models are in the order; BCC-CM2-MR, BCC-ESM1, CanESM5, CESM2, CESM2-WACCM, CNRM-CM8-1, CNRM-ESM2-1, ECEarth-Veg, GFDL-CM4-gr1, GFDL-CM4-gr2, GFDL-ESM4, IPSL-CM6A-LR, MRI-ESM20 , SAMO UNICON and UKESMI1-0 

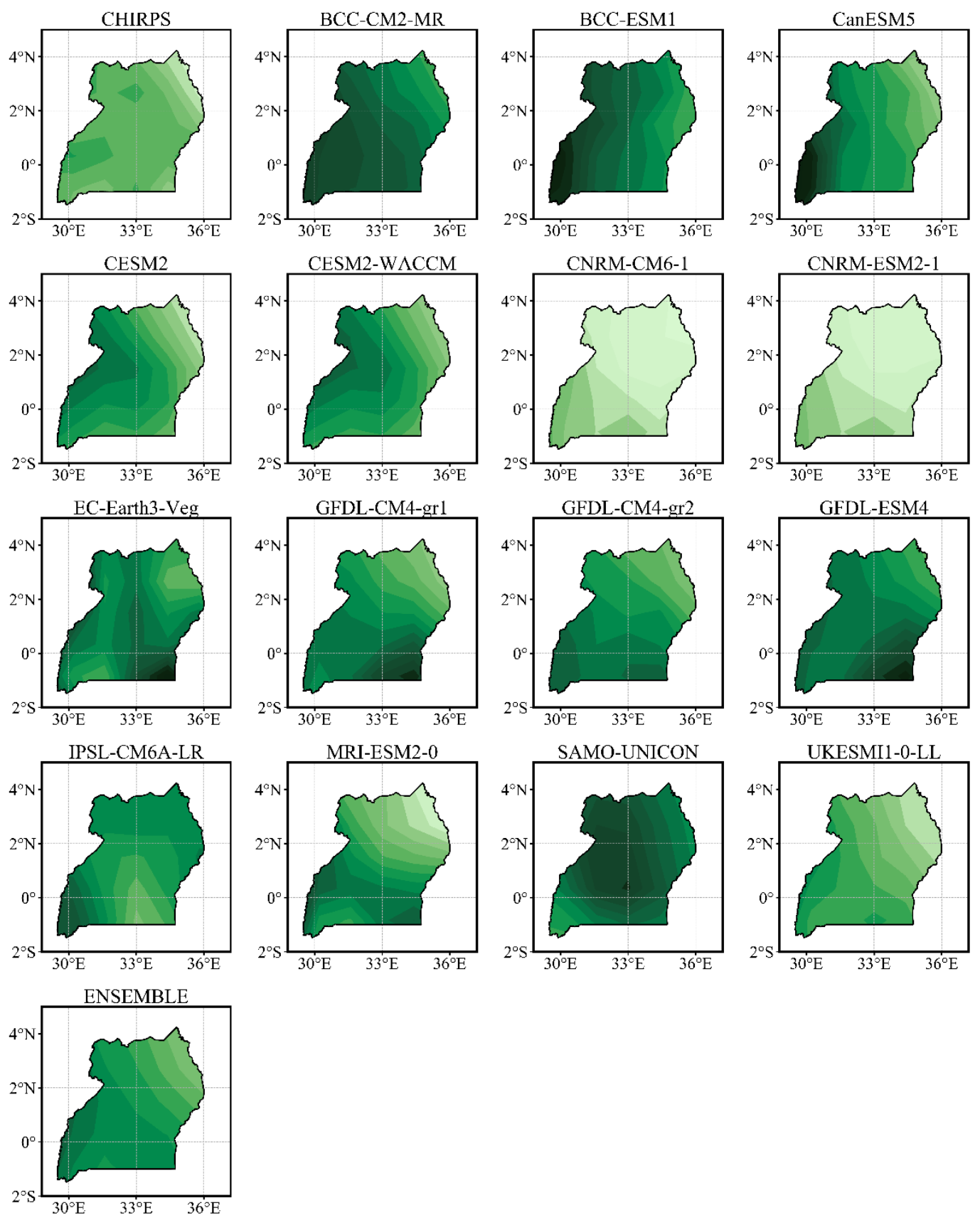

Figure 4. Same as Fig. 3 but for SON

\subsection{Temporal distribution}

The temporal distribution of CHIRPS and CMIP6 models-simulated rainfall for MAM and SON season is drawn in Figures 5 and 6, respectively. As shown in Figure 5a, the rainfall is distributed along a mean value of $129.89 \mathrm{~mm}$ and a standard deviation of $14.42 \mathrm{~mm}$. 10/15 models exhibit mean values higher than that observed with higher standard deviation. This justifies the models' poor performance as they tend to overestimate rainfall and exhibit more variability. Further, 5/15 models show the mean values lower than the CHIRPS records, 
implying that there is an underestimation of the mean rainfall. However, these models show relatively low standard deviation, thus replicating the temporal variability patterns of rainfall over the study domain. The MME mean exhibited the lowest standard deviation of $5.93 \mathrm{~mm}$, better capturing the temporal patterns of rainfall during MAM over the region. During SON, CHIRPS data reveal a low mean value of $113.62 \mathrm{~mm}$ and a standard deviation of $13.5 \mathrm{~mm}$. In addition, 13/15 models exhibit higher mean values than observed. The standard deviation of the models is also higher as compared to that for MAM. All the models show a standard deviation of less than $20 \mathrm{~mm}$, signifying more variability in rainfall received during SON. 

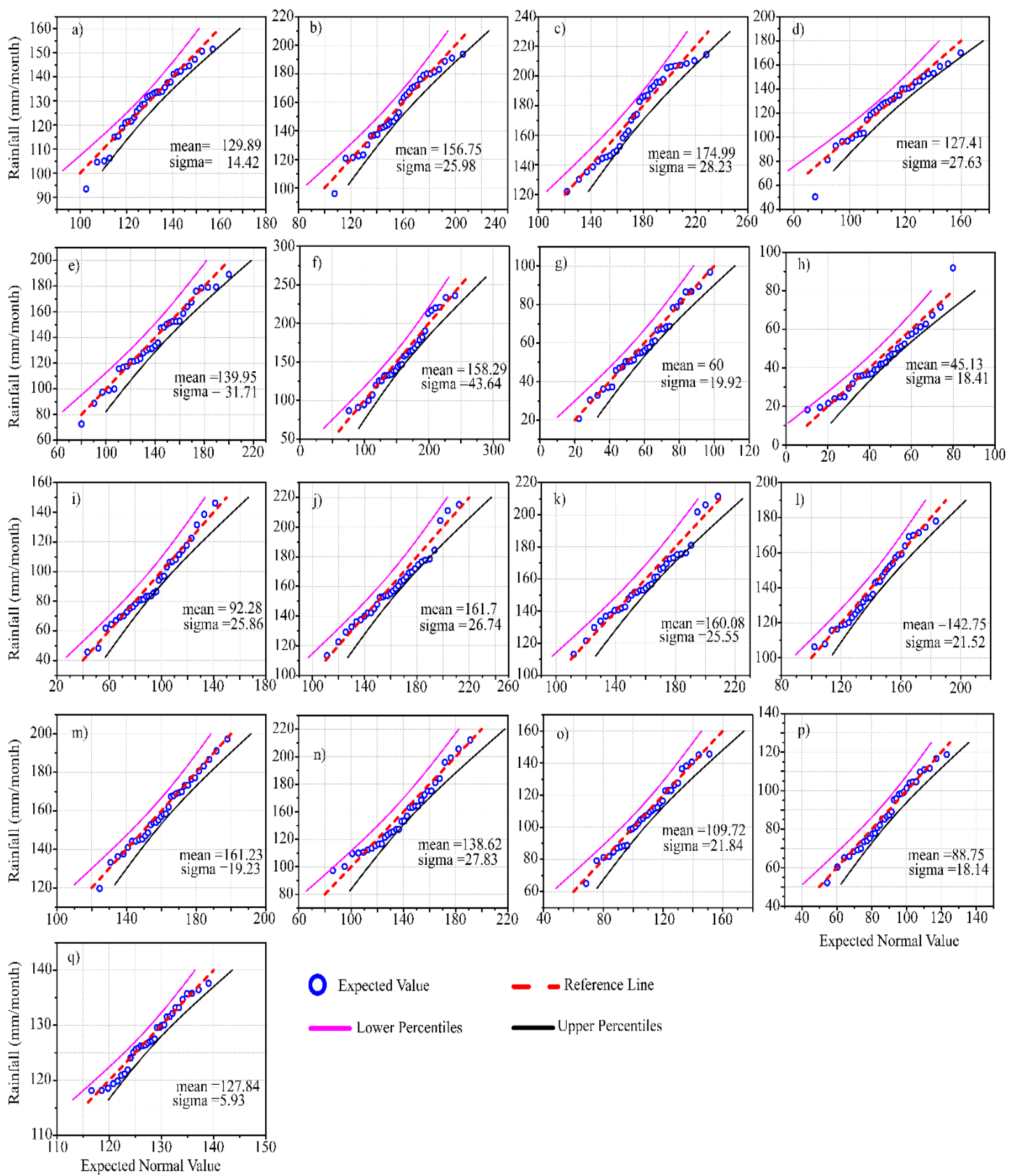

Figure 5. Temporal distribution of seasonal mean monthly precipitation for MAM over Uganda between 1981-2014 for CHIRPS (a), models (b-p) and ensemble (q). The models are in the order BCC-CM2-MR, BCC-ESM1, CanESM5, CESM2, CESME-WACCM, CNRM-CM6-1, CNRM-ESM2-1, EC-Earth-Veg, GFDL-CM4-gr1, GFDL-CM4-gr2, GFDL-ESM4, IPSLCM6A-LR, MRI-ESM2-0, SAMO UNICON and UKESMI1-0-LL. 

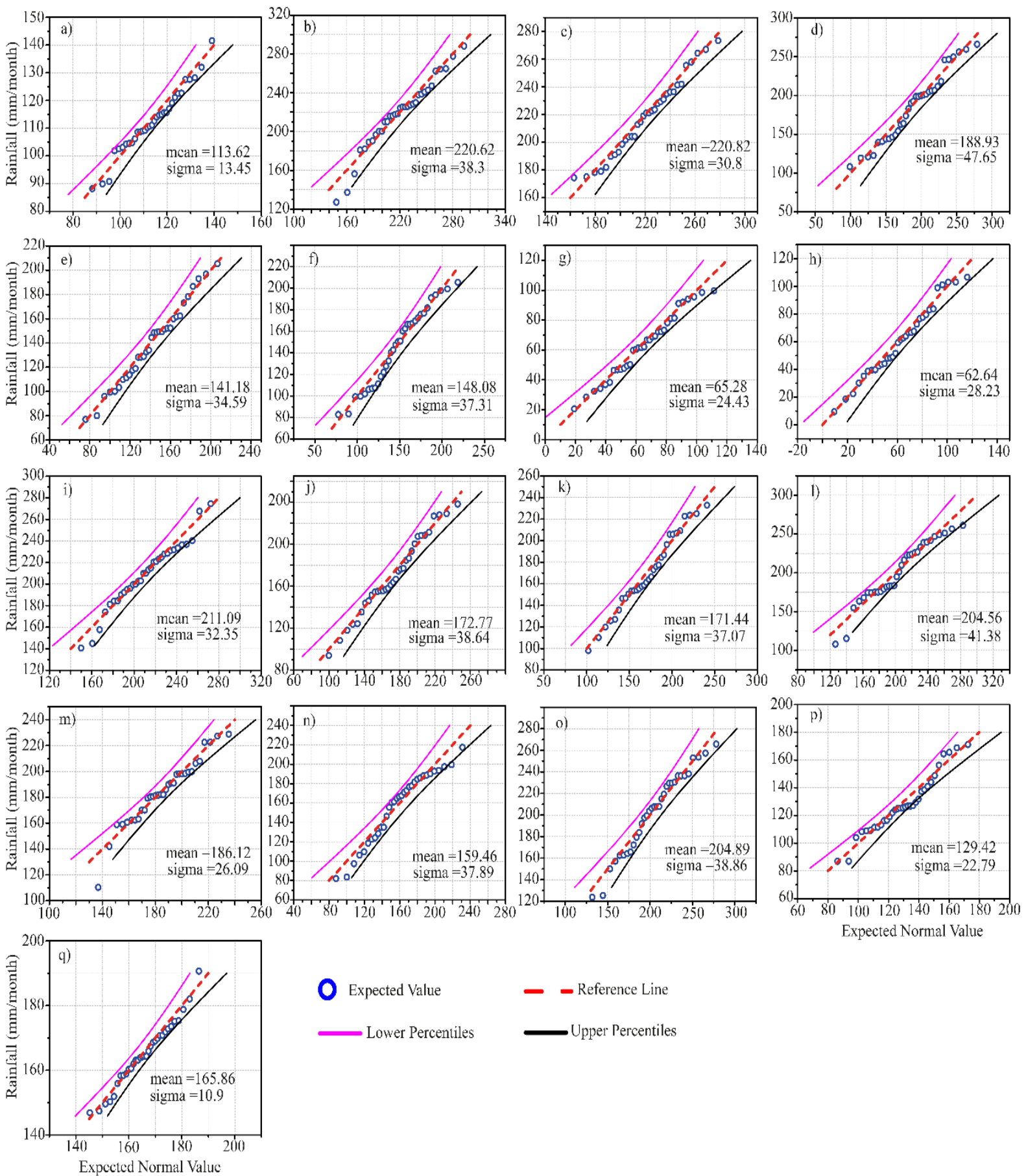

Figure 6. Same as Figure 5 but for SON

\subsection{Trend analysis}

The spatial patterns of the linear trend of mean rainfall for MAM and SON season are shown in Figures 7 and 8, respectively. A negative trend of less than $-0.8 \mathrm{~mm} /$ year is observed over most parts of the region, and a positive trend of less than $0.8 \mathrm{~mm} /$ year is observed in parts of 
the northeast, southwest, and central region in MAM (Figure 7). The ability of the models to reproduce the linear spatial trends varies from one model to another. Most of the models simulated the trends within the observed range's proximity except BCC-CM2-MR and UKESMI1-0-LL, which depict a higher positive MAM rainfall trend. Furthermore, as shown in Figure 8, a positive spatial linear trend of 0 to $1.2 \mathrm{~mm} / \mathrm{year}$ is observed over most parts of the region during the SON season. In total, 4/15 models depict a negative trend for SON rainfall. These include GFDL-CM4-gr1, GFDL-CM4-gr2, MRI-ESM2-0, and UKESMI1-0LL. However, the models CanESM5, BCC-ESM1, and CESM2-WACCM showed the highest positive linear trend for SON rainfall. Overall, the models well reproduce the spatial trends of rainfall during MAM than during SON. These results are attributed to the various SON rainfall mechanisms, such as ENSO, IOD, and quasi-biennial oscillation (QBO) (Nicholson, 1996,2017). These mechanisms cause high interannual variability in SON rainfall as compared to MAM. The poor representation of these mechanisms during model parameterization increases the model uncertainties in simulating rainfall patterns over the study region (Kent et al., 2015; Endris et al., 2016; Souverijns et al., 2016).

The trends were further evaluated and tested for their significance and magnitude. Table 2 shows the mean, slope, Z-score, and significance of linear trend of MAM and SON rainfall for CHIRPS and the 15 CMIP6 models. The rainfall over the region exhibits insignificant trends with a decreasing MAM trend and an increasing trend during SON. The mean (Z-score) values of $129.89 \mathrm{~mm}(0.24)$ and $113.62 \mathrm{~mm}(0.65)$ for MAM and SON, respectively, are observed in the CHIRPS datasets. These results agree with past studies over the study area (Kizza et al., 2009; Nsubuga et al., 2014; Ngoma et al., 2020). Only two models BCC-CM2MR and UKESMI1-0-LL, show a significant trend for MAM season with Z-scores of 2.19 $\mathrm{mm} / \mathrm{month}$ and $3.5 \mathrm{~mm} /$ month. The model ensemble slightly underestimates the mean rainfall for MAM with $127.89 \mathrm{~mm} /$ month but overestimates SON with $165.86 \mathrm{~mm} / \mathrm{month}$. On the other hand, all the models show insignificant decreasing and increasing trends for SON rainfall. The MME exhibits an insignifact increasing trend of $0.22 \mathrm{~mm} / \mathrm{year}$ with a Z-score of 1.04 .

MAM season is the main crop growing season over the study area. A decrease in rainfall during this season will have far-reaching negative impacts on the region's economy, which depends on rain-fed agriculture. This would be of significant effect as the rate of increase in rainfall for the MAM season exceeds the observed thus farmers could expect more rain but it later turns out less. The observed increase in the SON rainfall would benefit farmers by shifting the growing season to SON. However, this brings in other uncertainties as to the rain during this season is influenced by several mechanisms such as ENSO and IOD (Nicholson, 1996; 
Behera et al., 2006; Ogwang et al., 2015; Nicholson et al., 2017). These mechanisms lead to the SON rainfall exhibiting high interannual variability and is thus not completely reliable for rain-fed agriculture. The CMIP6 models also overestimate rainfall received during SON across the region.
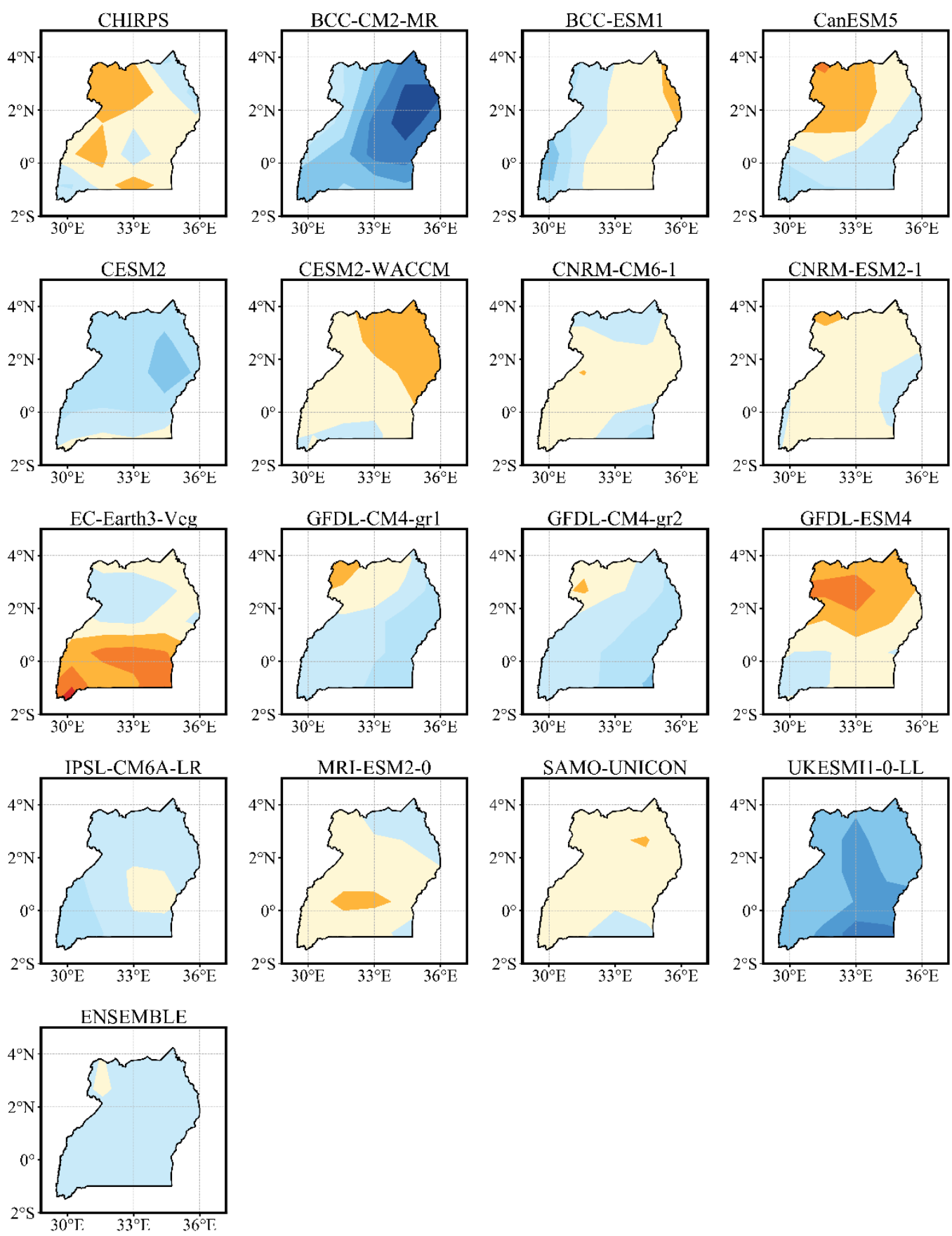

Figure 7. Spatial pattern of linear trends of MAM rainfall over Uganda during 1981-2014 based on CHIRPS, CMIP6 models and their ensemble mean. The models are in the order, BCCCM2-MR, BCC-ESM1, CanESM5, CESM2, CESM2-WACCM, CNRM-CM8-1, CNRM- 
ESM2-1, EC-Earth-Veg, GFDL-CM4-gr1, GFDL-CM4-gr2, GFDL-ESM4, IPSL-CM6A-LR, MRI-ESM2-0, SAMO UNICON and UKESMI1-0.
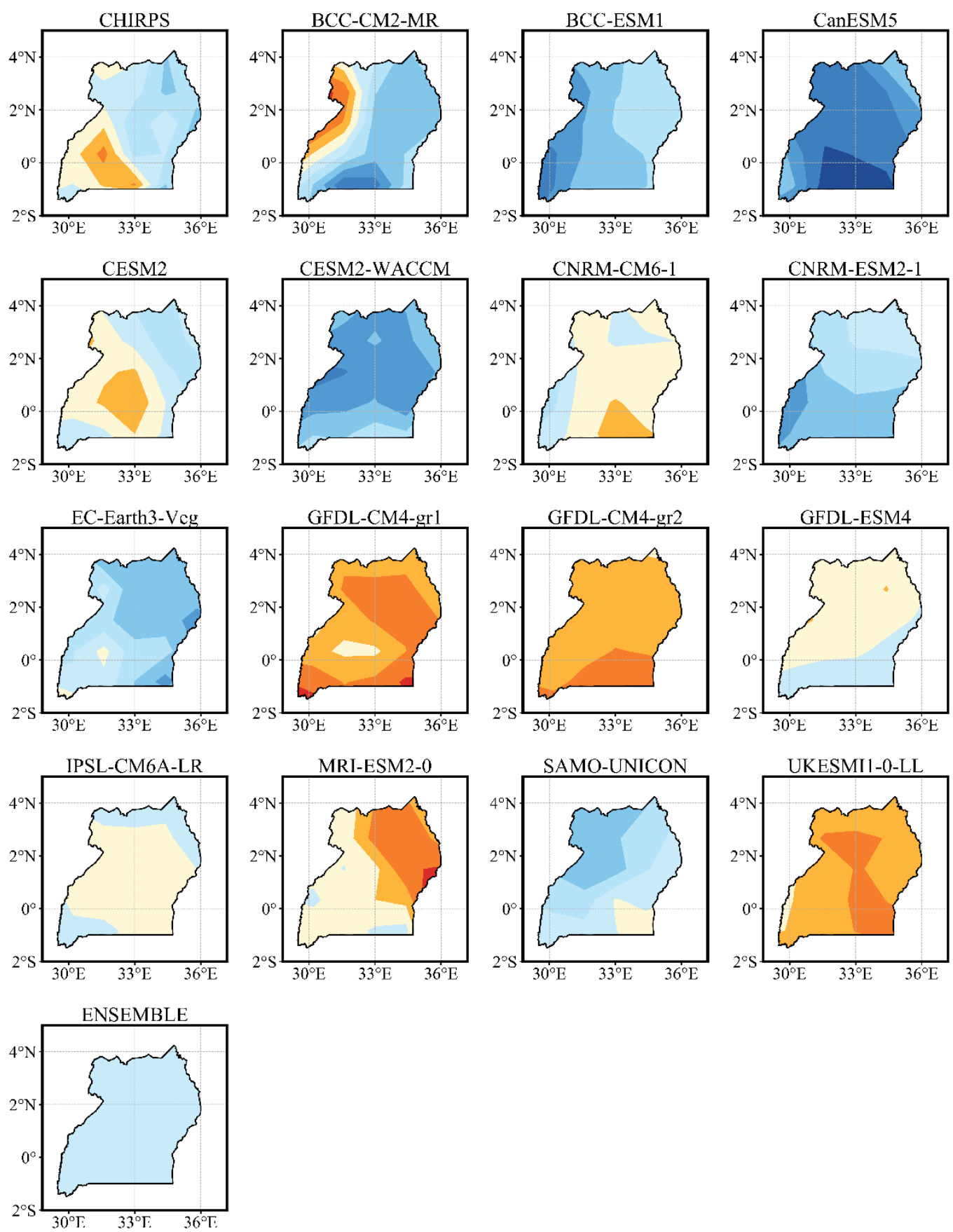

Figure 8. Same as of Figure 5 but for SON 
Table 2. Linear trend and Mann-Kendall trends of MAM and SON season mean rainfall over Uganda during 1981-2014 using the CHIRPS and CMIP6 models datasets. * indicates significant trend at $5 \%$ significance level.

\begin{tabular}{lrrrrrr}
\hline Model & \multicolumn{7}{c}{ MAM } & \multicolumn{3}{c}{ SON } & \\
\cline { 2 - 7 } & \multicolumn{1}{c}{ Mean } & Slope(mm/year) & Z-score & Mean & Slope(mm/year) & Z-score \\
CHIRPS & 129.89 & -0.16 & 0.24 & 113.62 & 0.17 & 0.65 \\
BCC-CM2-MR & 156.75 & 1.00 & $\mathbf{2 . 1 9}$ & 220.62 & 0.06 & 0.06 \\
BCC-ESM1 & 174.99 & 0.08 & 0.09 & 220.82 & 1.02 & 1.84 \\
CanESM5 & 127.41 & 0.24 & 0.36 & 188.93 & 1.65 & 1.90 \\
CESM2 & 139.95 & 0.18 & 0.46 & 141.18 & 0.03 & 0.0 \\
CESM2-WACCM & 158.29 & -0.30 & 0.50 & 148.08 & 0.86 & 1.22 \\
CNRM-CM6-1 & 60.00 & 0.08 & 0.21 & 65.28 & -0.1 & 0.18 \\
CNRM-ESM2-1 & 45.13 & -0.17 & 0.39 & 62.64 & 0.76 & 1.42 \\
EC-Earth-Veg & 92.28 & -0.46 & 1.13 & 211.09 & 0.71 & 1.10 \\
GFDL-CM4-gr1 & 161.70 & 0.41 & 0.98 & 172.77 & -0.53 & 0.68 \\
GFDL-CM4-gr2 & 160.08 & 0.34 & 0.89 & 171.99 & -0.48 & 0.74 \\
GFDL-ESM4 & 142.75 & -0.41 & 0.93 & 204.56 & -0.01 & 0.03 \\
IPSL-CM6A-LR & 161.23 & 0.31 & 0.77 & 186.11 & -0.04 & 0.21 \\
MRI-ESM2-0 & 138.62 & -0.12 & 0.21 & 159.46 & -0.44 & 0.53 \\
SAMO-UNICON & 109.72 & -0.11 & 0.21 & 204.89 & 0.29 & 0.50 \\
UKESMI1-0-LL & 88.75 & 1.20 & $\mathbf{3 . 5 0}$ & 129.42 & -0.61 & 1.45 \\
ENSEMBLE & 127.84 & 0.14 & 1.17 & 165.86 & 0.22 & 1.04 \\
\hline
\end{tabular}

\subsection{Statistical Analysis}

\subsubsection{Temporal Bias, RMSE and Correlation Coefficient metrics}

A model's performance is considered better if it exhibits low bias, small RMSE, and a higher positive correlation coefficient (CC). The metrics were analyzed and averaged over the study domain for MAM and SON seasons during the study period of 1981-2014, as shown in Figure 9.

During the MAM season (Figrure 9a), 5 of the models depict a dry rainfall bias over the region in the order CNRM-ESM2-1, CNRM-CM6-1, UKESMI1-0-LL, EC-Earth-Veg, and SAMO UNICON. The CNRM-ESM2-1 exhibits the highest dry bias of $>80 \mathrm{~mm}$ while the ensemble and CanESM5 simulate the MAM rainfall relatively well with a slightly lower dry bias of $<10 \mathrm{~mm}$. The rest of the models $(9 / 15)$ show a wet bias over the region during the MAM 
season. However, the bias was not so high in BCC-EM1, which simulates the highest wet bias of $<50 \mathrm{~mm}$. In addition, most of the models revealed a wet bias for the SON rainfall except two models, CNRM-ESM2-1 and CNRM-CM6-1. These two models' overall performance is poor in simulating rainfall over the region as they tend to underestimate the rainfall throughout the whole period. SAMO-UNICON, CESM, and CESM-WACCM perform well in simulating the SON rains with a relatively lower wet bias of $<40 \mathrm{~mm}$. The models' biases are usually attributed to the coarse resolution of the models, which could not capture the topographic effects and poor representation of convective schemes (Ongoma et al., 2019; Kisembe et al., 2019).

The RMSE of the CMIP6 models and ensemble employed in the study against CHIRPS data over the study domain is shown in Figure 9b. The models depict a relatively low RMSE when simulating rainfall for the MAM season as compared to SON. Only two models (CNRMESM2-1 and CNRM-CM6-1) show a high RMSE of >60 mm for the MAM season against CHIRPS data. However, most models reveal RMSE greater than the value mentioned above (>60 mm) in simulating the SON rainfall. The models with the highest RMSE for SON rains were in the order BCC-CM2-MR, BCC-ESM1, and EC-Earth-Veg. The ensemble and CanESM5 model show a low RMSE of $<30 \mathrm{~mm}$ for MAM, hence justifying their better performance. In addition, UKESMI1-0-LL reveals the lowest RMSE of $<40 \mathrm{~mm}$ in simulating the SON rains and shows the best performance than the rest of the models.

Figure 9c shows the models' correlation coefficient and ensemble relative to the CHIRPS dataset for MAM and SON rainfall over Uganda. Correlation identifies the ability of models to reproduce observed variable patterns. The higher the correlation coefficient, the better the performance of the models in replicating the observed patterns. About $7 / 15$ of the models and the ensemble reveal a positive correlation with observed patterns during the MAM season. The CNRM-CM6-1 shows the highest correlation of 0.44 when simulating the MAM rains. On the other hand, the remaining eight models showed negative correlations, with SAMO UNICOM showing the lowest correlation of -0.31 . For SON, the ensemble and 9 of the models showed positive correlations. The BCC-ESM1 reveals the highest correlation of 0.39 against CHIRPS data; thus, it replicates the observed patterns well. Furthermore, six models show negative correlations, with the CESM2 model depicting the lowest value of -0.41 . 
a)

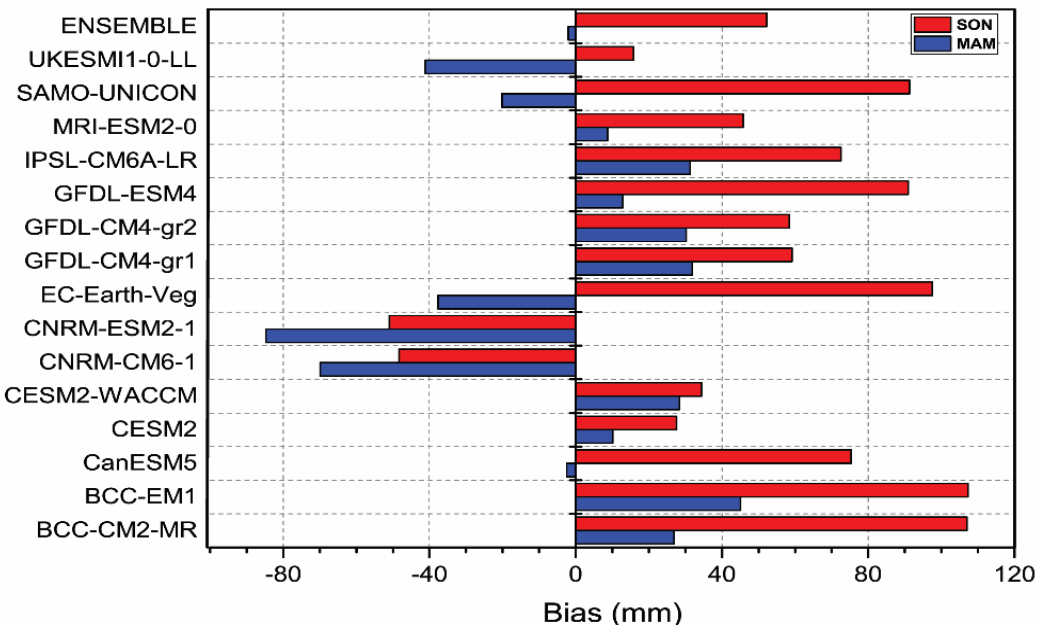

b)

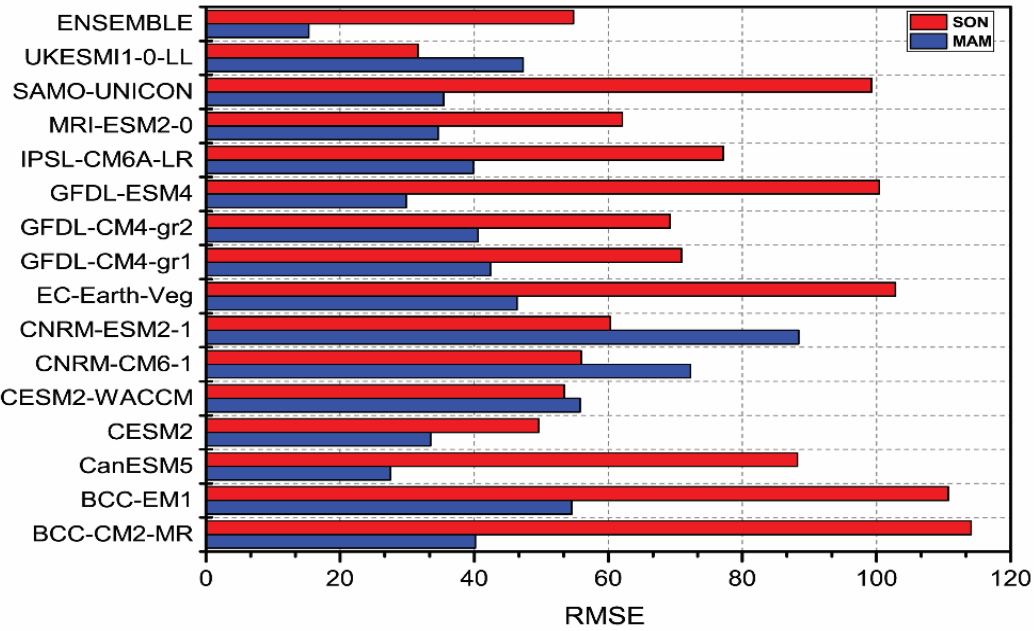

c)

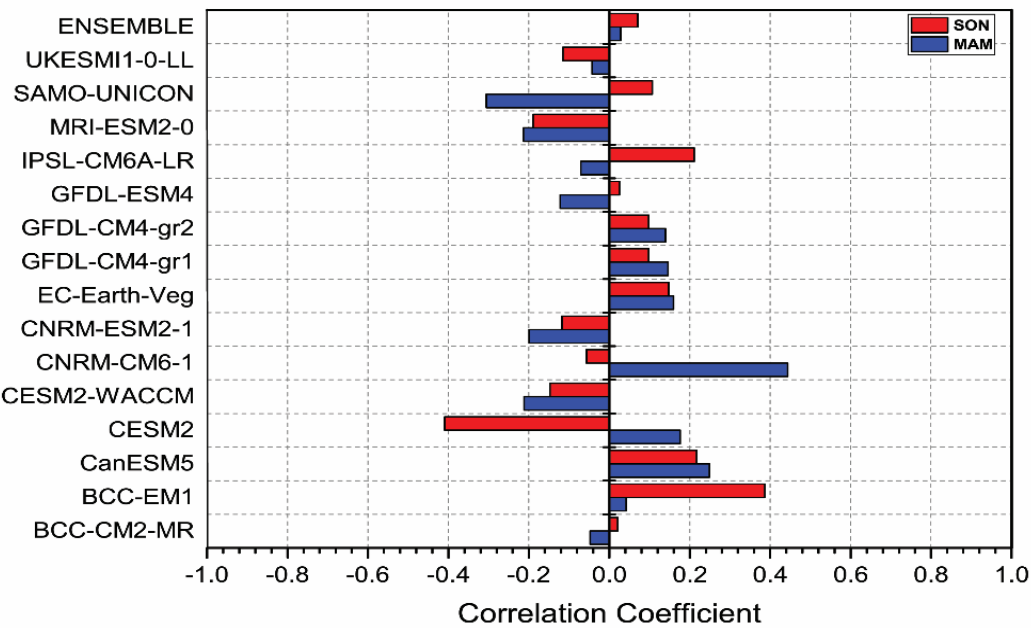

Figure 9. Temporal bias (a), RMSE (b) and Correlation coefficient of CMIP6 models and Ensemble against CHIRPS data for Uganda during 1981-2014 for MAM and SON rainfall. MAM is represented by blue and SON is represented by red. The models used include BCCCM2-MR, BCC-ESM1, CanESM5, CESM2, CESM2-WACCM, CNRM-CM8-1, CNRMESM2-1, EC-Earth-Veg, GFDL-CM4-gr1, GFDL-CM4-gr2, GFDL-ESM4, IPSL-CM6A-LR, MRI-ESM2-0, SAMO UNICON and UKESMI1-0 


\subsubsection{Spatial Annual Bias, RMSE and Correlation Coefficient}

The statistical metrics of bias, RMSE, and correlation coefficient of the GCMs simulated rainfall were averaged over the area against CHIRPs for the period 1981-2014 at the annual mean monthly scale shown in Figures 10-12. The bias results disclose a varying wet and dry biases by the models. The BCC-CM2-MR and BCC-ESM1 show the highest wet bias in the range of 10 to $140 \mathrm{~mm}$, hence depicting overestimation of rainfall over the region as shown in Figure 10. Further, CNRM-CM6-1 and CNRM-ESM2-1 reveal the highest dry bias in the range $-10 \mathrm{~mm}$ to $-140 \mathrm{~mm}$, signifying underestimation of observed rainfall over the study area. UKESMI1-0-LL performed relatively well in simulating rainfall patterns on the western part of the region with a minimum bias between -20 to $20 \mathrm{~mm}$. However, the model shows a higher dry bias when simulating rainfall on the eastern part. The ensemble mean exhibits the lowest bias in the range -20 to $40 \mathrm{~mm}$, except for a small area in the southwest where the bias was greater than $40 \mathrm{~mm}$.

RMSE is the difference between the GCMs simulation and the observed patterns regardless of the sign. The models generally exhibit varying differences in the current RMSE analysis. The ensemble and UKESMI-0-LL show the lowest RMSE, thus perform better in simulating annual rainfall patterns over most parts of the country. Although BCC-CM2-MR, BCC-ESM1, CESM2, and CESM2-WACCM show low RMSE on the eastern and northern parts, higher RMSE is depicted over the western and southern parts. The rainfall over these regions is not evenly distributed, and this is attributed to the effects of topography and mesoscale systems (Nsubuga et al., 2017). Thus, these mechanisms are not well captured by the parameterization and coarse resolution of the models.

All the models exhibit a positive correlation with observed spatial patterns of rainfall. In addition, the models correlate more positively with rainfall observed in the western parts of the region than in the eastern parts. The models' ensemble mean shows a strong positive correlation with the CHIRPS observed patterns. This justifies that the models performed well in simulating the observed patterns of rainfall over the study domain. The best performing models are BCC-CM2-MR, GFDL-CM4-gr1, GFDL-CM4-gr2, GFDL-ESM4, and UKESMI1-0-LL, while CESM2, CESM2-WACCM, CNRM-CM6-1, and CNRM-ESM2-1; the MRI-ESM2-0 exhibit low correlation with observed patterns. 

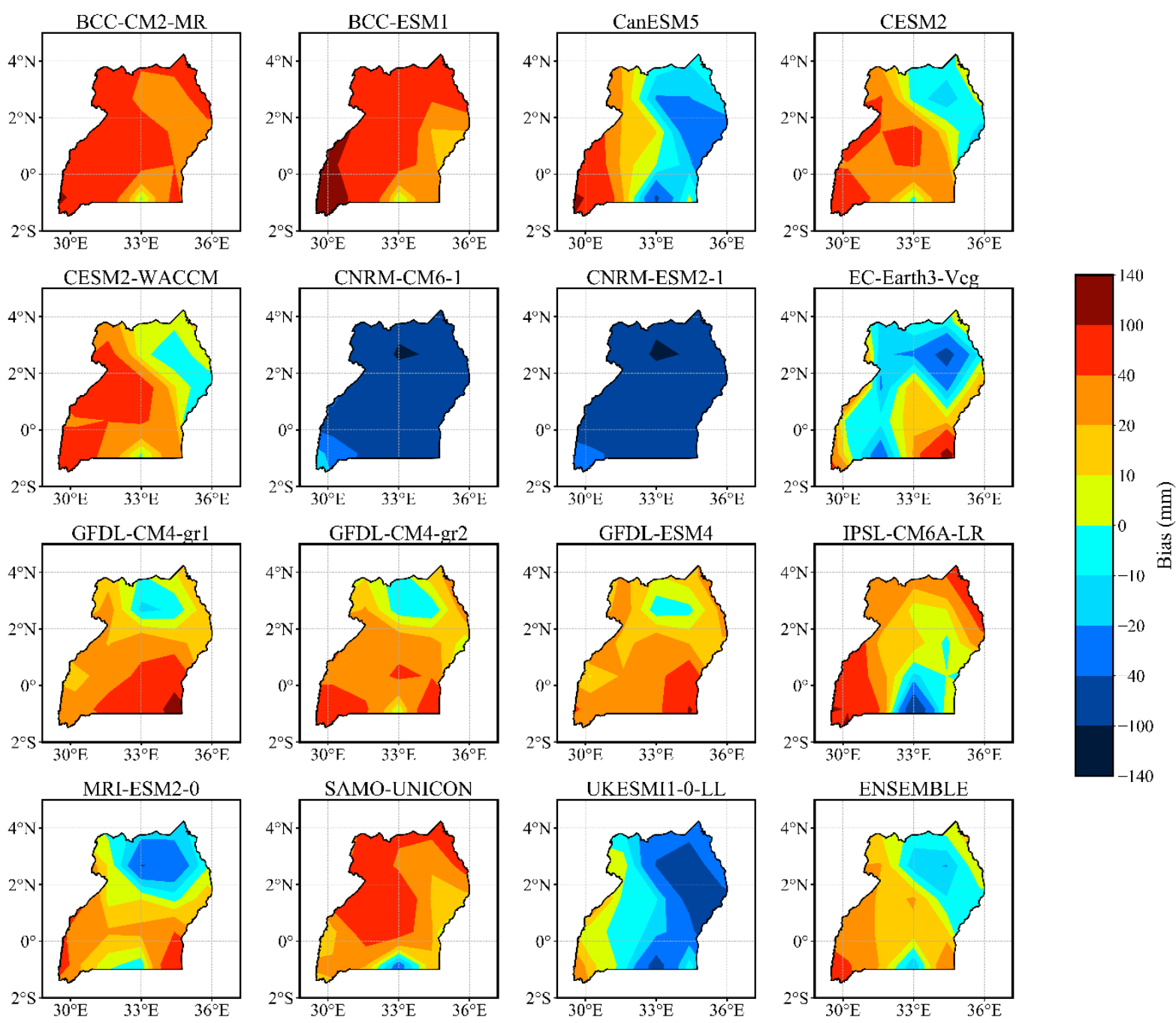

Figure 10. Annual spatial bias of CMIP6 models against CHIRPS data over Uganda for mean monthly annual rainfall for the period 1981-2014. The models utilized include BCC-CM2-MR, BCC-ESM1, CanESM5, CESM2, CESM2-WACCM, CNRM-CM8-1, CNRM-ESM2-1, ECEarth-Veg, GFDL-CM4-gr1, GFDL-CM4-gr2, GFDL-ESM4, IPSL-CM6A-LR, MRI-ESM20, SAMO UNICON and UKESMI1-0 

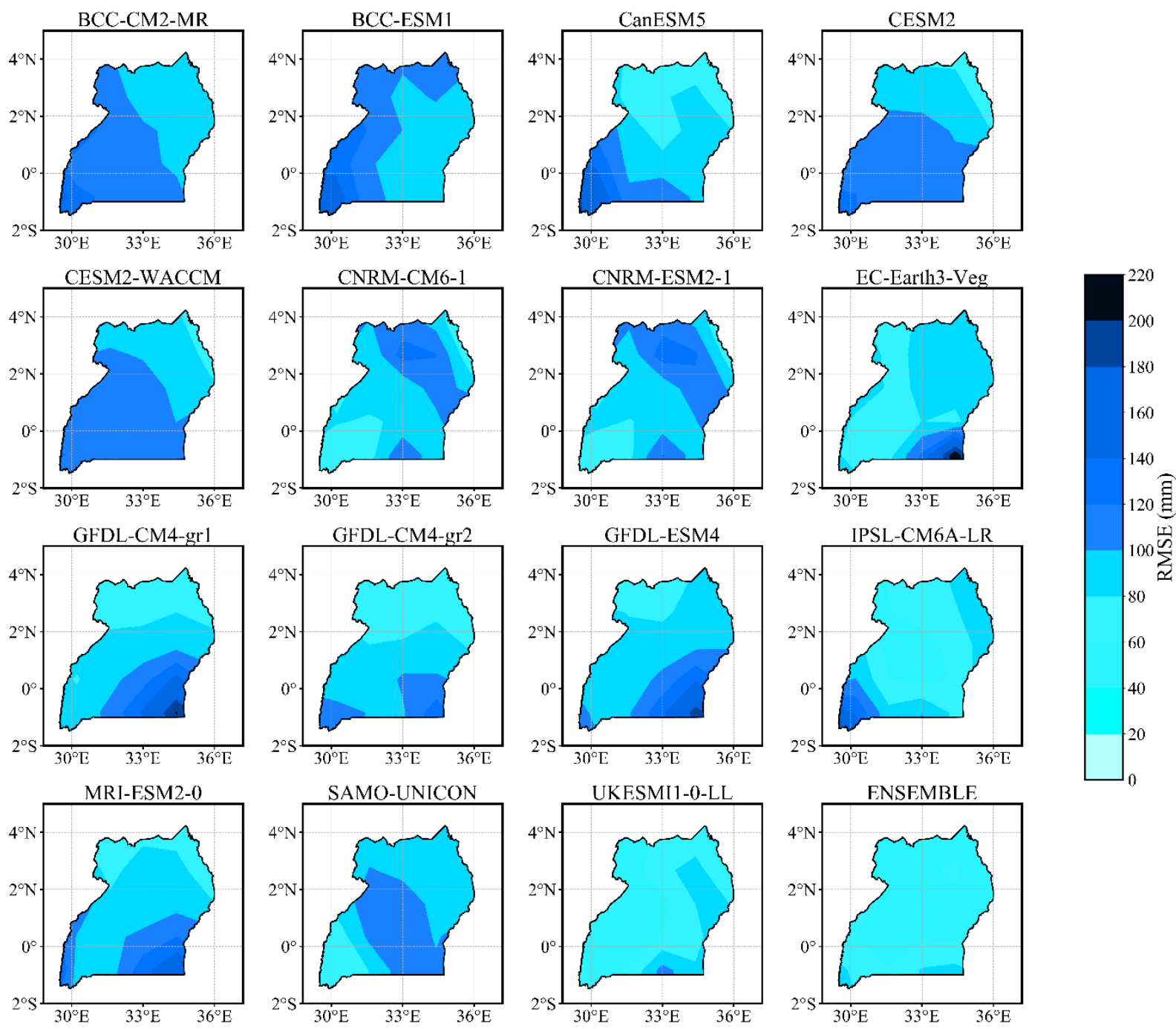

Figure 11. Annual spatial RMSE of CMIP6 models against CHIRPS data for mean monthly annual over Uganda for the period 1981-2014. The models utilized include BCC-CM2-MR, BCC-ESM1, CanESM5, CESM2, CESM2-WACCM, CNRM-CM8-1, CNRM-ESM2-1, ECEarth-Veg, GFDL-CM4-gr1, GFDL-CM4-gr2, GFDL-ESM4, IPSL-CM6A-LR, MRI-ESM20, SAMO UNICON and UKESMI1-0. 

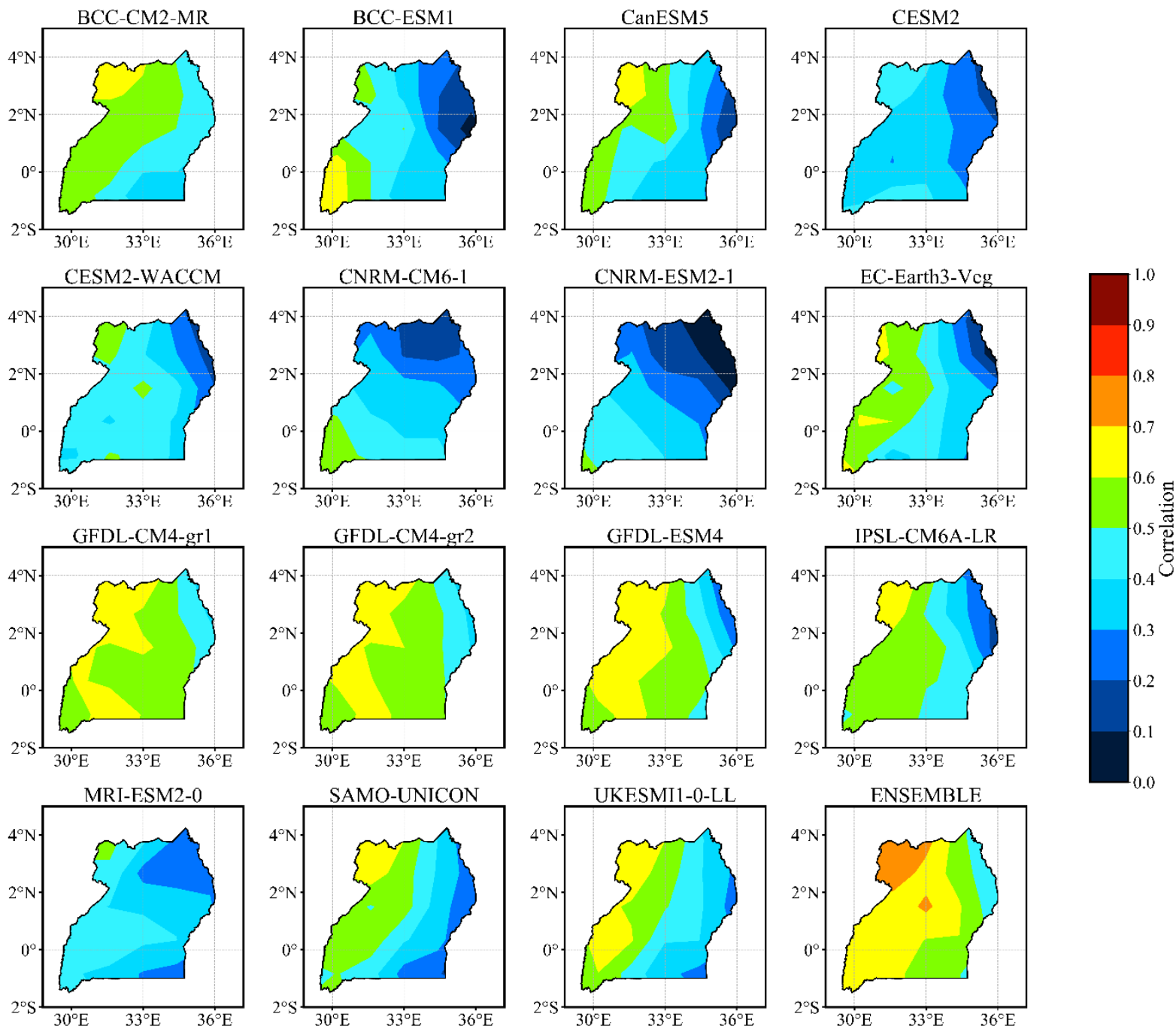

Figure 12. Spatial correlation coefficient of annual mean rainfall with CHIRPS of the GCMs over Uganda between 1981 and 2014. The models utilized include BCC-CM2-MR, BCCESM1, CanESM5, CESM2, CESM2-WACCM, CNRM-CM8-1, CNRM-ESM2-1, EC-EarthVeg, GFDL-CM4-gr1, GFDL-CM4-gr2, GFDL-ESM4, IPSL-CM6A-LR, MRI-ESM2-0, SAMO UNICON and UKESMI1-0.

\subsection{Model Ranking}

A summary of annual bias, RMSE, and the correlation coefficient is presented in Table 3. Most of the models tend to overestimate annual rainfall over the region. Only CNRM-CM6-1, CNRM-ESM2-1, and UKESMI1-0-LL show a negative bias, with a multi-model ensemble showing the lowest in reproducing annual rainfall over the region. Based on the lowest bias, the CanESM5, CESM2, CESM2-WACCM, EC-Earth-Veg, MRI-ESM2-0, and UKESMI1-0LL perform best. Generally, the RMSE is high in the range of 17.18 to 65.17 . The UKESMI10-LL shows the lowest RSME, while CNRM-ESM2-1 reveals the highest. The annual rainfall 
correlates negatively with 6 out of 15 models employed in the study. The positive correlation ranges between 0 and 0.41 , and the correlation of the models' ensemble with CHIRPS is 0.16 . As compared to over East Africa (Ongoma et al. 2019), there has been an improvement in the correlation of the models with observed patterns. In a related study, Ongoma et al. (2019) evaluated the performance of CMIP5 in simulating rainfall over East Africa against Climatic Research Unit (CRU) datasets. The positive correlation between the models with CRU was low, ranging from 0.01 to 0.24 , where even the ensemble mean had a negative correlation.

Table 3. Summary skill score of CMIP6 model performance for annual temporal scale against CHIRPS data over Uganda during 1981-2014.

\begin{tabular}{lrrr}
\hline Model & \multicolumn{1}{c}{ Bias } & RMSE & Correlation \\
\cline { 2 - 4 } BCC-CMC-MR & 51.01 & 53.64 & 0.02 \\
BCC-ESM1- & 59.68 & 61.61 & 0.18 \\
CanESM5 & 15.94 & 20.7 & 0.40 \\
CESM2 & 15.14 & 26.44 & 0.02 \\
CESM2-WACCM & 16.13 & 27.73 & -0.16 \\
CNRM-CM6-1 & -58.34 & 59.41 & 0.1 \\
CNRM-ESM2-1 & -63.60 & 65.17 & -0.33 \\
EC-Earth-Veg & 15.38 & 20.55 & 0.40 \\
GFDL-CM4-gr1 & 22.51 & 28.78 & -0.06 \\
GFDL-CM4-gr2 & 22.33 & 28.21 & -0.07 \\
GFDL-ESM4 & 23.57 & 29.11 & -0.03 \\
IPSL-CM6A-LR & 32.78 & 34.53 & 0.27 \\
MRI-ESM2-0 & 16.78 & 23.01 & -0.12 \\
SAMO-UNICON & 20.87 & 25.96 & 0 \\
UKESMI1-0-LL & -14.52 & 17.18 & 0.41 \\
ENSEMBLE & 11.71 & 14.33 & 0.16 \\
\hline
\end{tabular}

Taylor diagram was used in ranking the CMIP6 models score for simulating spatial seasonal and annual mean rainfall over the region. Figure 13 shows the models' performance in correlating with the observed patterns, the centered RMSD, and the ability of the models to reproduce the variability in rainfall quantified by the standard deviation. Overall, most models perform better in reproducing SON season rainfall than MAM rainfall (Figure 13). These results agree with a previous study by Ongoma et al. (2019), which utilized the CMIP5 models over East Africa. The better performance in the current study is attributed to the underlying mechanisms influencing rainfall over the region. Rainfall during SON is largely driven by 
large-scale features such as ENSO and IOD, which are captured by the GCMs. All the models positively correlated with the observed data for both MAM and SON seasons. Only one model, CNRM-CM6-1, had a negative correlation relative to observation when simulating annual rainfall. In selecting the best performing models, we employed the Taylor skill score (TSS) shown in Figure 14. The closer TSS's value is to 1, the better the agreement between the simulation and observation. The range of TSS of the models during MAM is $0.51-0.78$, whereas during SON is $0.62-0.85$. However, the models exhibit poor performance in simulating annual rainfall patterns over the region with the TSS ranging between $0.14-0.74$. During MAM, GFDL-ESM4 shows the highest score, and IPSL-CM6A-LR depicted the poorest performance. The CNRM-CM6A-1 reveals the highest score, and CESM2-WACCM shows the least performance during SON. The BCC-CMC-MR exhibits the best performance, while CNRM-CM6A-1 exhibits the poorest at an annual scale. The best performing models during MAM are (figure 14) in the order GFDL-ESM4, CESM2-WACCM, BCC-CM2-MR, UKESMI1-0-LL, EC-Earth-Veg, SAMO UNICON, BCC-ESM1, and CanESM5. During SON, the best performing models include CNRM-ESM2-1, CNRM-CM6-1, BCC-CM2-MR, IPSLCM6A-LR, GFDL-ESM4, EC-Earth-Veg, GFDL-CM4-gr1, CanESM5, and GFDL-CM4gr2.

In addition, for annual rainfall, the best performing models include BCC-CM2-MR, MRI-ESM2-0, IPSL-CM6A-LR, GFDL-ESM4 and GFDL-CM4-gr2. Generally, the performance of the models in reproducing rainfall over the study region varies from one season to the other. In addition, poor performance is exhibited when reproducing observed annual rainfall patterns than seasonal. It is noted that some of the models which exhibit good performance could not well reproduce the seasonal climatology and linear trends of rainfall over the study domain. Thus, the best performing models include GFDL-ESM4, BCC-CMCMR, IPSL-CM6A-1, CanESM5 GDFL-CM4-gr1 and GFDL-CM4-gr2. Studies by Ongoma et al. (2019) and Mumo and Yu (2020) using the CMIP5 over East Africa reported that CanESM5 exhibited the best performance in reproducing the MAM rainfall. However, in the present study, more models outperformed CanESM5 during MAM. Thus, more improvement is exhibited by the CMIP6 models in reproducing rainfall over the study domain. 

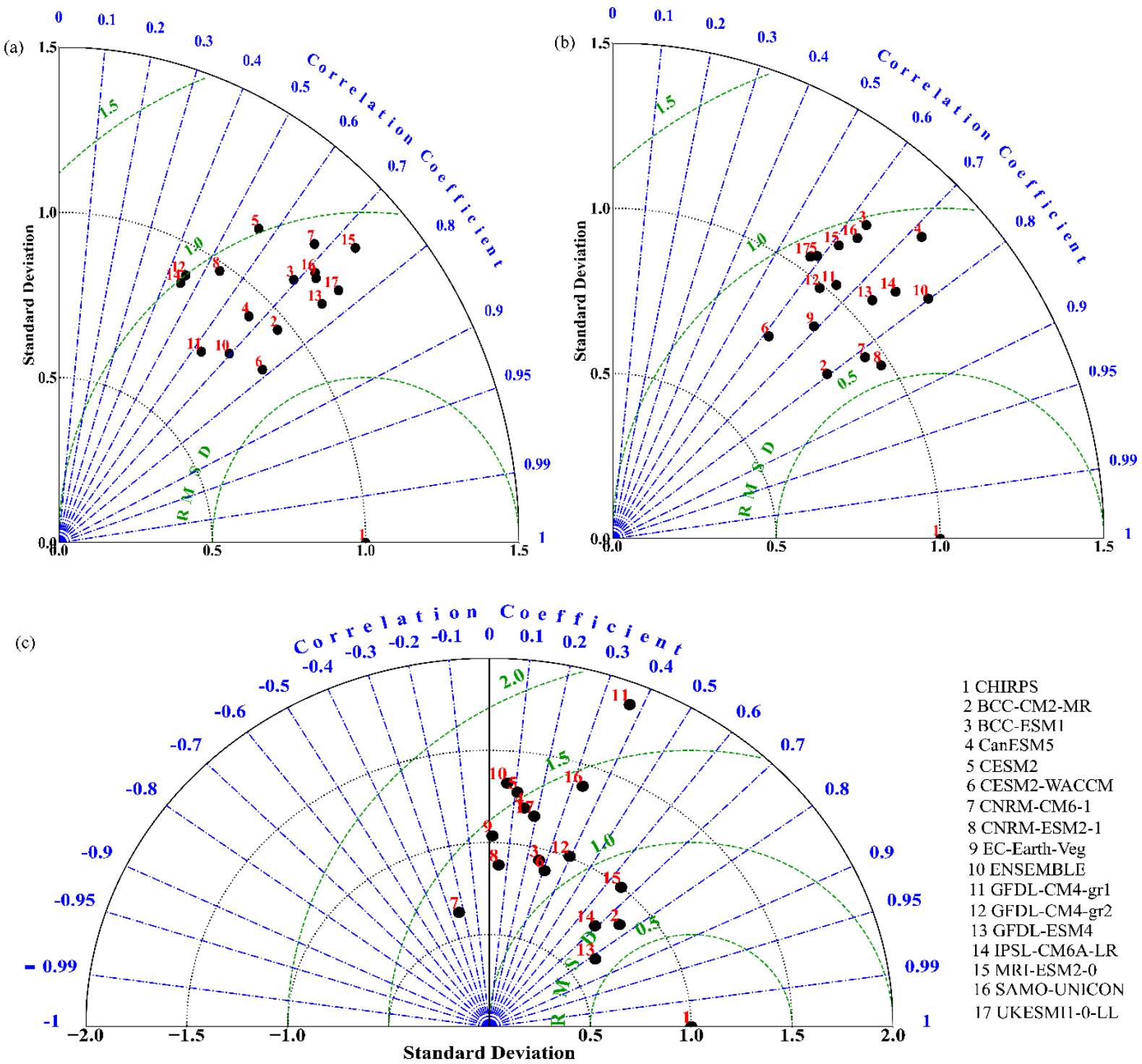

Figure 13. Taylor Diagram for models' score for (a) MAM, (b) SON and (c) Annual rainfall over Uganda during 1981-2014 of CMIP6 models against CHIRPS data. The models utilized include BCC-CM2-MR, BCC-ESM1, CanESM5, CESM2, CESM2-WACCM, CNRM-CM81, CNRM-ESM2-1, EC-Earth-Veg, GFDL-CM4-gr1, GFDL-CM4-gr2, GFDL-ESM4, IPSLCM6A-LR, MRI-ESM2-0, SAMO UNICON and UKESMI1-0. 
(a)

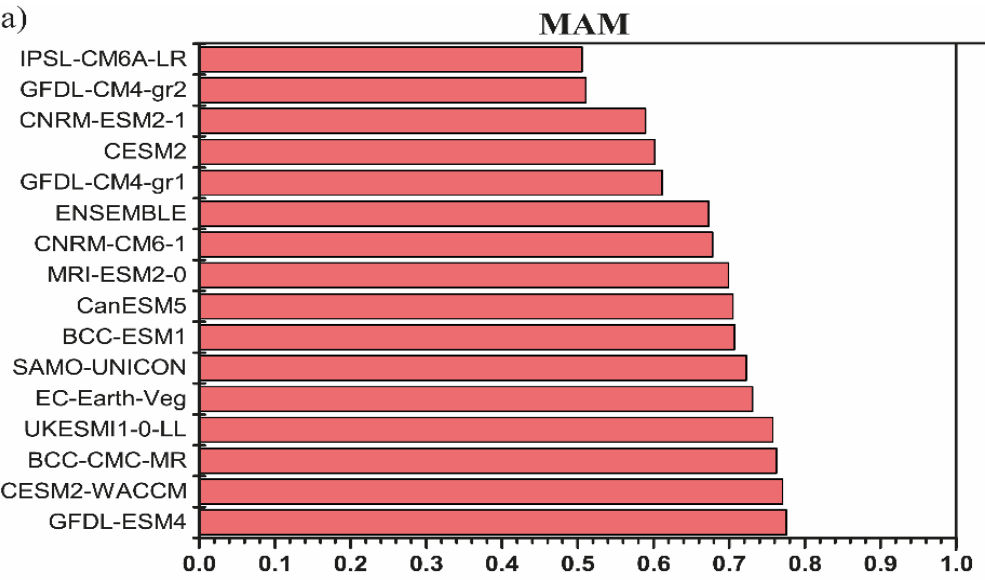

(b)

TSS

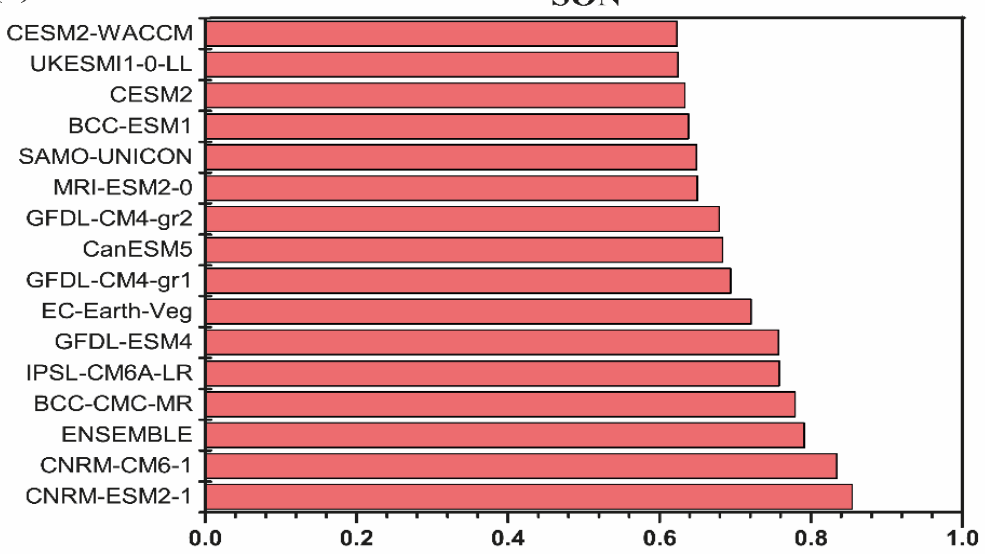

TSS

(c)

ANNUAL

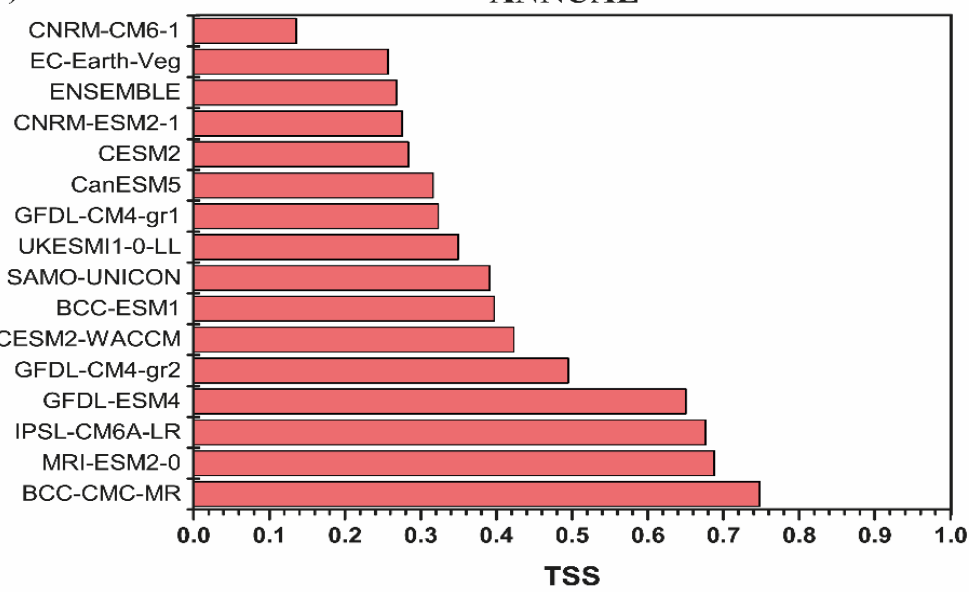

Figure 14. Taylor Skill Score (TSS) of the CMIP6 models and ensemble mean against CHIRPS rainfall data over Uganda for the period 1981-2014 for MAM (a), SON (b) and annual (c). The models utilized include BCC-CM2-MR, BCC-ESM1, CanESM5, CESM2, CESM2-WACCM, CNRM-CM8-1, CNRM-ESM2-1, EC-Earth-Veg, GFDL-CM4-gr1, GFDL-CM4-gr2, GFDL-ESM4, IPSL-CM6A-LR, MRI-ESM2-0, SAMO UNICON and UKESMI1-0. 


\section{Summary and conclusion}

Rainfall is the most essential weather parameter in the tropics as it affects many socioeconomic activities. Uganda's national economy largely depends on rain-fed agriculture, so any slight fluctuation in rainfall will have far-reaching effects on the community livelihoods. Understanding its patterns in variability and trends is crucial for predicting likely patterns and structuring effective adaption and mitigation strategies and climate change policies.

In this study, we evaluated 15 GCMs of the CMIP6 and their ensemble mean in reproducing mean rainfall over the country at annual and seasonal scales. In the study, only the first run of the first realization of the models was considered. The models were re-gridded to a common grid of $1^{\circ} \times 1^{\circ}$ spatial resolution. The models and the ensemble mean were compared against CHIRPS dataset as a proxy to observation for the period 1981 - 2014 by evaluating their ability to reproduce the climatology, linear trends, temporal distribution, and important statistical metrics.

The models tend to reproduce well the bimodal rainfall pattern regime received over the country. The results revealed that some models slightly overestimated, while others slightly underestimated, the MAM rainfall. In addition, the most models highly overestimated the short rains. Previous studies have also noted this over East Africa with CMIP5 (Ongoma et al., 2019; Mumo and $\mathrm{Yu}, 2020)$. The SON rains have been reported to exhibit higher interannual variability (Nicholson 2017; Kisembe et al., 2019; Egeru et al., 2019; Ngoma et al., 2020) as compared to MAM by many past studies. This is attributed to the fact that SON rainfall is regulated by global teleconnections such as ENSO and IOD. Therefore, more research is necessary to understand the mechanisms governing precipitation over Uganda (e.g., landatmosphere interaction) and how models simulate them. The two models, CNRM-CM6-1 and CNRM-ESM2-1, tend to underestimate rainfall throughout the years. The performance of the models varies from seasonal to annual scale. Most models exhibited good performance during SON than MAM according to the TSS model's ranking. The models further depicted a reduction in dry bias compared to CMIP5 in simulating MAM rainfall. Nevertheless, some of the models that showed good performance in the ranking could not simulate well the seasonal climatology of the study region. With all that put into consideration, the best performing models include GFDL-ESM4, BCC-CMC-MR, IPSL-CM6A-LR, CanESM5, GDFL-CM4gr1, and GFDL-CM4-gr2. The spatial correlation of the models with CHIRPS is positive at seasonal and annual scales, but a negative correlation is depicted for interannual variability. 
The findings of this study are of great importance to climatologists and end-users of the datasets. The results will help producers improve parameterization schemes in the models, where the models could not reproduce the observed patterns well. There is still a need for improvement in the models to minimize biases resulting from topography and local-scale convective effects. For the end-users, more caution is needed when using CMIP6 outputs in projecting rainfall during SON, as most models tend to overestimate it. However, the model outputs are generally reproducing rainfall consistent with observed datasets during MAM, and thus can be adopted in future rainfall projection during MAM over Uganda.

Author Contributions: Conceptualization, H.N and B.A.; methodology, H.N and B.A.; software, H.N, B.A and H.B.; validation, H.N., H.B., and B.A.; formal analysis, H.N, R.K., B.A and H.B.; investigation, B.A, V.O.; resources, B.A.; data curation, H.N.; writing —original draft preparation, H.N.; writing-review and editing, H.N., B.A., W.W., H.B., R.K and V.O.; visualization, H.N., B.A., R.K., H.B.; supervision, W.W.; project administration, W.W., and B.A.; funding acquisition, B.A.

Funding: National Key Research and Development Program of China (2017YFA0603804), National Natural Science Foundation of China (41575070) supported this work.

\section{Acknowledgments}

The authors are grateful to Nanjing University of Information Science and Technology for providing a favorable working environment and structural and technological support for conducting the research. We also acknowledge the data centers which availed the datasets employed in the study; the World Climate Research Programme and the Climate Hazards Center. The first author is thankful to the Ministry of Commerce of the People's Republic of China for granting her a scholarship to pursue Masters studies.

\section{Compliance with ethical standards}

All authors declare no conflict of interest in the present study

\section{References}

Ahmed, K., Sachindra, D.A., Shahid, S., Demire, M.C., Chung, E., 2019. Selection of multi model ensemble of general circulation models for the simulation of precipitation and maximum and minimum temperature based on spatial assessment metrics. Hydrol. Earth Syst. Sci., 23,4803-4824. https://doi.org/10.5194/hess-23-4803-2019 
Akinsanola, A.A., Ajayi, V.O., Adejare, A.T., Adeyeri, O.E., Gbode, I.E., Ogunjobi, K.O, Nikulin, G., Abolude, A.T., 2017. Evaluation of rainfall simulations over West Africa in dynamically downscaled CMIP5 global circulation models. Theor Appl Climatol 132:437-450. https://doi.org/10.1007/s00704-017-2087-8

Akinsanola, A.A., Kooperman., G.J., Pendergrass, A.G., Hannah, W.M., Reed, K.A., 2020. Seasonal representation of extreme precipitation indices over the United States in CMIP6 present-day simulations. Environ. Res. Lett. 15, 094003. https://doi.org/10.1088/17489326/ab92c1

Akurut, M., Willems, P., Niwagaba, C.B., 2014. Potential impacts of climate change on precipitation over Lake Victoria, East Africa, in the $21^{\text {st }}$ Century. Water 6, 2634-2659

Almazroui, M., Saeed, S., Saeed, F., Islam, M.N., Ismail, M., 2020a. Projections of Precipitation and Temperature over the South Asian Countries in CMIP6. Earth Systm Environ. https://doi.org/10.1007/s41748-020-00157-7

Almazroui. M., Saeed, S., Saeed, F., Islam, M.N., Ismail, M., Klutse, N.A.B, Siddiqui, M.H., 2020b. Projected Change in Temperature and Precipitation Over Africa from CMIP6. Earth Systm Environ. https://doi.org/10.1007/s41748-020-00161-X

Asadullah, A., Mcintyre, N., Kigobe, M., 2008. Evaluation of five satellite products for estimation of rainfall over Uganda. Hydrological Sciences Journal. 53, 6: 1137-1150.

Ayugi, B., Tan, G., Gnitou, G.T., Ojara, M., Ongoma, V., 2020. Historical evaluations and simulations of precipitation over East Africa from Rossby centre regional climate model. Atmos Res 232(2020): 104705 https://doi.org/10.1016/j.atmosres.2019.104705

Ayugi. B., Tan, G., Ullah, W., Boiyo, R., Ongoma, V., 2019. Inter-comparison of remotely sensed precipitation datasets over Kenya during 1998-2016. Atmos Res 225:96-109. https://doi.org/10.1016/j.atmosres.2019.03.032

Basalirwa, C.P.K., 1995 Delineation of Uganda into climatological rainfall zones using the method of principal component analysis. Int. J. Climatol 15:1161-1177. https://doi.org/10.1002/joc.3370151008

Behera, S.K., Luo, J.J., Masson, S., Delecluse, P., Gualdi, S., Navarra, A., Yamagata, T., 2006. Erratum: Paramount impact of the Indian ocean dipole on the East African short rains: A CGCM J. Climate 18:4514-4530. https://doi.org/10.1175/JCLI3541.1

Boucher, O., Denvil, S., Caubel, A., Foujols, M.A., 2018. IPSL IPSL-CM6A-LR model output prepared for CMIP6 CMIP historical Earth System Grid Federation (https://doi.org/10.22033/ESGF/CMIP6.5195) 
Bowden, R., 2007. Kenya, $2^{\text {nd }}$ edition. Evan Brothers, London, UK.

Danabasoglu, G., 2019b. NCAR CESM2-WACCM model output prepared for CMIP6 CMIP historical Earth System Grid Federation (https://doi.org/10.22033/ESGF/CMIP6.10071)

Dinku, T., Funk, C., Peterson, P., Maidment, R., Tadesse, T., Gadain, H., Ceccato, P., 2018. Validation of the CHIRPS satellite rainfall estimates over eastern Africa. Q J R Meteorol Soc. 2018;144 (Suppl. 1):292-312. DOI: 10.1002/qj.3244

EC-Earth., 2019. EC-earth-consortium EC-Earth3-Veg model output prepared for CMIP6 $\begin{array}{lllll}\text { CMIP historical } & \text { Earth }\end{array}$ (https://doi.org/10.22033/ESGF/CMIP6.727)

Egeru, A., Barasa, B., Nampijja, J., Siya, A., Makooma, M.T., Majaliwa, M.G.J., 2019. Past, Present and Future Climate Trends Under Varied Representative Concentration Pathways for a Sub-Humid Region in Uganda. J. Climate, 7(35) https://doi.org/10.3390/cli7030035

Endris, H.S., Omondi, P., Jain, S., Lennard, C., Hewitson, B., Chang'a, L., Awange, J.L., Dosio, A., Ketiem, P., Nikulin, G., Panitz, H.J., Büchner, M., Stordal, F., Tazalika, L., 2013. Assessment of the performance of CORDEX regional climate models in simulating East African rainfall. J. Climate 26:8453-8475. https://doi.org/10.1175/JCLI-D-12$\underline{00708.1}$

Endris, H.S., Lennard, C., Hewitson, B., Dosio, A., Nikulin, G., Panitz, H.J., 2016. Teleconnection responses in multi-GCM driven CORDEX RCMs over Eastern Africa. Clim Dyn, 46, 2821-2846. DOI 10.1007/s00382-015-2734-7

Eyring, V., Bony, S., Meehl, G.A., Senior, C., Stevens, B., Stouffer, R.J., Taylor, K.E., 2016. Overview of the Coupled Model Intercomparison Project Phase 6 (CMIP6) experimental design and organisation. Geosci. Model Dev. 9:1937-1958. https://doi.org/10.5194/gmdd$\underline{\text { 8-10539-2016 }}$

Funk, C., Peterson, P., Landsfeld, M., Pedreros, D., Verdin, J., Shukla, S., Husak, G., Rowland, J., Harrison, L., Hoell, A., Michaelsen, J., 2015 The climate hazards infrared precipitation with stations - A new environmental record for monitoring extremes. Scientific Data 2: 121. https://doi.org/10.1038/sdata.2015.66

Government of Uganda, GOU., 2015. Economic Assessment of the Impacts of Climate Change in Uganda. Final Study Report. Ministry of Water and Environment, Climate Change Department, Kampala. https://cdkn.org/wp-content/uploads/2015/12/Uganda_CCeconomics_Final-Report2.pdf

Guo, H., et al., 2018. NOAA-GFDL GFDL-CM4 model output prepared for CMIP6 CMIP historical Earth System Grid Federation (https://doi.org/10.22033/ESGF/CMIP6.1402 
Indeje, M., Semazzi, F.H.M., Xie, L., Ogallo, L.J., 2 001. Mechanistic model simulations of the East African climate using NCAR regional climate model: Influence of large-scale orography on the Turkana low-level jet. J. Climate, 14(12), 2710-2724. doi.org/10.1175/1520-0442(2001)014<2710:MMSOTE>2.0.CO;2.

IPCC., 2012. Changes in climate extremes and their impacts on the natural physical environment. Managing the Risks of Extreme Events and Disasters to Advance Climate Change Adaptation. A Special Report of Working Groups I and II of the Intergovernmental Panel on Climate Change, S. I. N. Nicholls, et al., Eds., Cambridge University Press, 109230.

IPCC., 2013. Climate Change 2013: The Physical Science Basis. Contribution of Working Group I to the Fifth Assessment Report of the Intergovernmental Panel on Climate Change, T. F. Stocker, et al., Eds., Cambridge University Press.

Isaaks, E.H., Srivastava, R.M., 1989. Applied Geostatistics. Oxford University Press, New York, $561 \mathrm{pp}$.

Karim, R., Tan, G., Ayugi, B., Babaousmail, H., Lui F., 2020. Evaluation of Historical CMIP6 Model Simulations of Seasonal Mean Temperature over Pakistan during 1970-2014. Atmosphere. 2020, 11, 1005. doi:10.3390/atmos11091005.

Kendall, M.G., 1975. Rank correlation methods, 4th edn. Griffin, London, p 202

Kent C, Chadwick R, Rowell DP (2015) Understanding uncertainties in future projections of seasonal tropical precipitation. J Clim 28(11):4390-4413. https://doi.org/10.1175/JCLI-D$14-00613.1$

Kim, J., Ivanov, V. Y., Fatichi, S., 2015. Climate change and uncertainty assessment over a hydroclimatic transect of Michigan, Stoch. Environ. Res. Risk Assess., 30, 923-944

Kisembe, J., Favre, A., Dosio, A., Lennard, L., Sabiiti, G., Nimusiima, A., 2018. Evaluation of rainfall simulations over Uganda in CORDEX regional climate models. Theor. Appl. Climatol. 137(1-2), 1117-1134. https://doi.org/10.1007/s00704-018-2643-X

Kizza, M., Rodhe, A., Xu, C.Y., Ntale, H.K., Halldin, S., 2009. Temporal rainfall variability in the Lake Victoria Basin in East Africa during the twentieth century. Theor appl climatol 98: 119-135. https://doi.org/10.1007/s00704-008-0093-6

Krasting, J.P et al., 2018. NOAA-GFDL GFDL-ESM4 model output prepared for CMIP6 CMIP historical https://doi.org/10.22033/ESGF/CMIP6.8597.doi:10.22033/ESGF/CMIP6.8597 
Luo, N., Guo, Y., Gao, Z., Chen, K., Chou, J., 2020. Assessment of CMIP6 and CMIP5 model performance for extreme temperature in China, Atmospheric and Oceanic Science Letters, DOI: $10.1080 / 16742834.2020 .1808430$

Mann, H.B., 1945. Nonparametric tests against trend. Econometrica 13:245-259

Mugume, I., Waiswa, D., Mesquita, M.D.S., Reuder, J., Basalirwa., C et al., 2017. Assessing the Performance of WRF Model in Simulating Rainfall over Western Uganda. J Climatol Weather Forecasting 5: 197. doi:10.4172/2332-2594.1000197

Mulinde, C., Majaliwa, J.G.M., Twesigomwe, E., Egeru, A., 2016. Meteorological Drought Occurrence and Severity in Uganda. In B. R. Nakileza, Y. Bamutaze, \& P. Mukwaya (Eds.), Disasters and Climate Resilience in Uganda: Processes, Knowledge and Practices (pp. 185-215). Kampala, Uganda: UNDP.

Mumo, L., Yu, J., 2020. Gauging the performance of CMIP5 historical simulation in reproducing observed gauge rainfall over Kenya. Atmos Res. 236 (2020): 104808 https://doi.org/10.1016/j.atmosres.2019.104808

Ngoma, H., Wen, W., Ojara, M., Ayugi, B., 2020. Assessing current and future spatiotemporal precipitation variability and trends over Uganda, East Africa based on CHIRPS and Regional Climate Models Datasets. Meteorol. Atmospheric Phys. Under press

Nicholson, S. E., 1996. A review of climate dynamics and climate variability in eastern Africa, in The Limnology, Climatology, and Paleoclimatology of the East African Lakes, edited by T. C. Johnson and E. O. Odada, pp. 25-56, Gordon and Breach Publ., Amsterdam.

Nicholson, S. E., 2017. Climate and climatic variability of rainfall over eastern Africa, Rev. Geophys., 55, 590-635, doi:10.1002/2016RG000544.

Nicholson, S.E., 2018. The ITCZ and the Seasonal Cycle over Equatorial Africa. Bull. Amer. Meteor. Soc. 99 (2): 337-348. https://doi.org/10.1175/BAMS-D-16-0287.1

Nsubuga, F.N.W., Olwoch, J.M., de Rautenbach, C.J.W., Botai, O.J., 2014. Analysis of midtwentieth century rainfall trends and variability over southwestern Uganda. Theor appl climatol 115:53-71. https://doi.org/10.1007/s00704-013-0864-6

Nsubuga, F.N.W., Rautenbach, H., 2017. Climate change and variability: a review of what is known and ought to be known for Uganda. Int. J Clim Chang Str. 10(5): 752-771 DOI 10.1108/IJCCSM-04-2017-0090

Ogwang, B.A., Chen, H., Li, X., Gao, C., 2014. The influence of topography on East African October to December climate: Sensitivity experiments with RegCM4. Adv. Meteorol https://doi.org/10.1155/2014/143917 
Ogwang, B.A., Chen, H., Li, X., Gao, C., 2016. Evaluation of the capability of RegCM4 in simulating East African climate. Theor Appl Climatol 124(1-2):303-313

Ogwang, B.A., Chen, H., Tan, G., Ongoma, V., Ntwali, D., 2015. Diagnosis of East African climate and the circulation mechanisms associated with extreme wet and dry events: a study based on RegCM4. Arab J Geosci 8(12):10255-10265. https://doi.org/10.1007/s12517-015-1949-6

Ojara, M.A., Lou, Y., Aribo, L., Namumbya, S., Uddin, M.J., 2020. Dry spells and probability of rainfall occurrence for Lake Kyoga Basin in Uganda, East Africa. Nat Hazards 100: 493-514. https://doi.org/10.1007/s11069-019-03822-X

Ongoma, V., Chen, H., 2017. Temporal and spatial variability of temperature and precipitation over East Africa from 1951 to 2010. Meteorol Atmos Phys 129:131-144. https://doi.org/10.1007/s00703-016-0462-0

Ongoma, V., Chen, H., Gao, C., 2019. Evaluation of CMIP5 $20^{\text {th }}$ century rainfall simulation over the Equatorial East Africa. Theor Appl Climatol 135:893-910

Onyutha, C., Tabari, H., Rutkowska, A., Nyeko-Ogiramoi, P., Willems, P., 2016. Comparison of different statistical downscaling methods for climate change rainfall projections over the Lake Victoria basin considering CMIP3 and CMIP5. J Hydro-environ Res 12: 31-45.

Onyutha, C., Tabari, H., Rutkowska, A., Nyeko-Ogiramoi, P., Willems, P., 2019. How well do climate models reproduce variability in observed rainfall? A case study of the Lake Victoria basin considering CMIP3, CMIP5 and CORDEX simulations. Stochastic Environmental Research and Risk Assessment. 33(3), 687-707. https://doi.org/10.1007/s00477-018-1611-4

Osima, S., Indasi, V.S., Zaroug, M., Endris, H.S., Gudoshava, M., Misiani, H.O., Dosio, A., 2018. Projected Climate over Greater Horn of Africa under $1.5^{\circ} \mathrm{C}$ and $2^{\circ} \mathrm{C}$ global warming. Environ. Res. Lett.13 (6). https://doi.org/10.1128/JVI.74.13.6223-6226.2000

Park, S., Shin, J., 2019. Snu sam0-unicon model output prepared for CMIP6 CMIP historical

Saji, N.H., Goswami, B.N., Vinayachandran, P.N., Yamagata, T., 1999. A dipole mode in the tropical Indian ocean. Nature 401: 360-363. https://doi.org/10.1038/43854

Séférian, R., Nabat, P., Michou, M., Saint-Martin, D., Voldoire, A., Colin, J., et al., 2019. Evaluation of CNRM Earth-System model, CNRMESM2-1: role of Earth system processes in present-day and future climate. $\mathrm{J}$ Adv Model Earth Syst. https://doi.org/10.1029/2019MS001791

Sen, P.K., 1968. Estimates of the regression coefficient based on Kendall's tau. J. Am.Stat. Assoc. 63, 1379-1389. https://doi.org/10.2307/2285891. 
Sneyers, R., 1990. On the Statistical Analysis of a Series of Observations. Tech Note 143: WMO-No. 415, 192

Sperber, K., Palmer, T., 1996. Interannual tropical rainfall variability in general circulation model simulations associated with the Atmospheric Model Intercomparison Project. J. Clim. 9, 2727-2750 doi:10.1175/15200442(1996)009 < 2727:ITRVIG > 2.0.CO;2.

Souverijns, N., Thiery, W., Demuzere, M., Lipzig, N.P.M. Van., 2016. Drivers of future changes in East African precipitation Drivers of future changes in East African precipitation. Environ. Res. Lett., 11 (11), 114011.https://doi.org/doi:10.1088/1748$\underline{9326 / 11 / 11 / 114011}$

Swart, N.C., et al., 2019. The Canadian Earth System Model version 5 (CanESM5.0.3)

Sylla, M.B., Giorgi, F., Coppola, E., Mariotti, L., 2012. Uncertainties in daily rainfall over Africa: assessment of gridded observation products and evaluation of a regional climate model simulation. Int J Climatol 33: 1805-1817. https://doi.org/10.1002/joc.3551

Tang, Y., Rumbold, S., Ellis, R., Kelley, D., Mulcahy, J., Sellar, A., Walton, J., Jones, C., 2019. Mohc ukesm1.0-1l model output prepared for CMIP6 CMIP historical Earth System Grid Federation (https://doi.org/10.22033/ESGF/CMIP6.6113)

Taylor, K.E., 2001. Summarizing multiple aspects of model performance in a Single Diagram. J. Geophys. Res 106:7183-7192. https://doi.org/10.1029/2000JD900719

Taylor, K.E., Stouffer, R.J., Meehl, G.A., 2012. An overview of CMIP5 and the experiment design. Bull. Amer. Meteorol. Soc., 93: 485-498. doi:10.1175/BAMS-D-11-00094.1

Tebaldi, C., Knutti, R., 2007. The use of the multi-model ensemble in probabilistic climate projections. Phil. Trans. R. Soc. A (2007) 365, 2053-2075. doi:10.1098/rsta.2007.2076

Voldoire, A., et al., 2019. Evaluation of CMIP6 DECK experiments with CNRM-CM6-1 J. Adv. Model Earth Syst.11 2177-213

Williams, A.P., Funk, C., 2011. A westward extension of the warm pool leads to a westward extension of the Walker circulation, drying eastern Africa. Clim dyn 37: 2417-2435. https://doi.org/10.1007/s00382-010-0984-y

Wu, T., Chu, W., Dong, M., Fang, Y., Jie, W., Li J., Li, W., Liu, Q., Shi, X., Xin, X., Yan, J., Zhang, F., Zhang, J., Zhang, L., Zhang, Y., 2018. BCC BCC-CSM2MR model output prepared for CMIP6 CMIP historical Earth System Grid Federation. https://doi.org/10.22033/ESGF/CMIP6.2948.

Xin, X., Wu, T., Zhang, J., Yao, J., Fang, Y., 2020. Comparison of CMIP6 and CMIP5 simulations of precipitation in China and the East Asian summer monsoon. Int J Climatol. 2020;1-18. https://doi.org/10.1002/joc.6590 
Yang, W., Seager, R., Cane, M.A., Lyon, B., 2014. The East African long rains in observations and models. J Clim 27(19):7185-7202

Yang, W., Seager, R., Cane, M.A., Lyon, B., 2015. The rainfall annual cycle bias over East Africa in CMIP5 coupled climate models. J Clim 28(24):9789-9802. https://doi.org/10.1175/JCLI-D-15-0323.1

You, Q., Jiang, Z., Wang, D., Pepin, N., Kang, S., 2018. Simulation of temperature extremes in the Tibetan Plateau from CMIP5 models and comparison with gridded observations, Clim. Dynam., 51, 355-369.

Yukimoto, S., et al., 2019. MRI MRI-ESM2.0 model output prepared for CMIP6 CMIP historical Earth System Grid Federation (https://doi.org/10.22033/ESGF/CMIP6.621)

Zhang, J., et al., 2018. BCC BCC-ESM1 model output prepared for CMIP6 CMIP historical Earth System Grid Federation. https://doi.org/10.22033/ESGF/CMIP6.2949.

Zhu, H.H., Jiang, Z.H., LI, J., Li, W., Sun, C.X., Li, L., 2020. Does CMIP6 inspire more confidence in simulating climate extremes over China? Adv. Atmos. Sci., 37(10), 11191132, https://doi.org/10.1007/s00376-020-9289-1. 